\title{
Prácticas campesinas en un contexto feudalizado: las relaciones de benefactoría (siglos XI y XII)
}

\section{Peasant Practices in a Feudal Context: The relations of Benefactoria (11th and 12th centuries)}

\author{
Laura DA GRAÇA \\ Universidad de La Plata- Universidad de Buenos Aires \\ lauradagraca@gmail.com
}

\begin{abstract}
RESUMEN
Las relaciones de benefactoría del siglo XI expresan prácticas sociales derivadas del modo de producción campesino. Estas prácticas (dotación de tierras, padrinazgo, mediación en disputas interfamiliares, elección de jefe, hospitalidad) se desarrollan en los intersticios de un espacio feudalizado, por lo cual tienden a modificar sus contenidos. La transmutación de la práctica campesina es el mecanismo por el cual la relación de explotación feudal y sus formas políticas conquistan espacios libres. Este proceso concluye, en el área castellano-leonesa, hacia mediados del XII, momento en que se verifica la incorporación plena de estas formas sociales al modo de producción feudal.
\end{abstract}

Palabras clave: Benefactoría. Prácticas campesinas. Padrinazgo. Mediación en disputas familiares. Elección de jefe. Hospitalidad

\begin{abstract}
The relations known as benefactoria express social practices derived from the peasant mode of production. These practices (grants of land for services, fosterage, arbitration in family disputes, the election of a chief, hospitality) are performed in the interstices of a space already feudalized, in which they tend to modify their contents. The transmutation of peasant practices is the mechanism through which relations of feudal exploitation and their forms conquest free spaces. In the area of Castile-Leon, this process concludes in the second half of the 12th century, when these social forms are fully incorporated into the feudal mode of production.
\end{abstract}

Keywords: Benefactoria. Peasant practices. Fosterage. Arbitration. Election of chief. Hospitality

Sumario: La dotación de tierras a cambio de servicios. Las relaciones de crianza o padrinazgo. La mediación en conflictos interfamiliares y la actuación de los benefactores en la asamblea. La facultad de elección de jefe. La práctica de la hospitalidad y la exigencia de tributos. Conclusiones. 
La documentación del siglo XI del área castellano-leonesa y de otras regiones registra pactos en los cuales personas de diversa condición formalizan vínculos no permanentes con miembros de la aristocracia. Esta relación se conoce como benefactoría, y ha sido considerada desde diversas perspectivas ${ }^{1}$.

Para Sánchez Albornoz la benefactoría es una modalidad de encomendación por la cual un campesino libre cede sus tierras a cambio de protección, manteniendo el usufructo de su parcela y la libertad de cambiar de señor. Esta forma de encomendación territorial convive con otro género de patrocinio, también referido como benefactoría, donde el que requiere protección es dotado con tierras². A estas dotaciones se refieren mayormente los historiadores actuales que estudian el problema. Martínez Sopena considera la benefactoría como una forma de prestimonio o una cesión en precario donde es más incierta la identidad del señor, debido a la vigencia de un principio electivo ${ }^{3}$. Para el autor estas cesiones consisten mayormente en lotescorvea, debiendo cumplir el cesionario prestaciones de trabajo; la benefactoría se asociaría a la puesta en cultivo de la reserva ${ }^{4}$. Estepa Díez entiende que los beneficiados con dotaciones de tierras (que no son necesariamente prestimonios) no eran sólo campesinos sino también milites; la benefactoría se presentaría como una forma de dependencia personal, no territorial, entre miembros de la alta nobleza y sectores de la nobleza inferior o del campesinado libre que tenían la capacidad de elegir señor ${ }^{5}$. Otros historiadores concuerdan con esta caracterización, según la cual la relación de benefactoría es una forma social laxa que expresa cierto grado de libertad ${ }^{6}$. Por último, Luis Martínez García entiende la benefactoría como una modalidad de servidumbre, sistema que identifica con la prestación de servicios a cambio de protección. El autor conjetura que la benefactoría es la forma universal de inserción señorial en las comunidades y un vehículo de dominación; Martínez no admite para el vocablo seruitium otra interpretación que la de renta señorial?

1 Agradezco los comentarios de Chris Wickham y Carlos Astarita.

2 SÁnchez Albornoz, Claudio, "Las behetrías", en Viejos y nuevos estudios sobre las instituciones medievales españolas, I, Madrid, 1976. Sánchez-Albornoz desestima estas dotaciones como antecedente de la behetría y como forma social, dado el predominio, en el periodo en cuestión, de hombres libres propietarios sin problemas de instalación.

${ }^{3}$ Martínez Sopena, Pascual, La Tierra de Campos Occidental. Poblamiento, poder y comunidad del siglo X al XIII, Valladolid, 1985, p. 239.

${ }^{4}$ Martínez Sopena, Pascual, "Parentesco y poder en León durante el siglo Xi. La 'casata' de Alfonso Díaz", Studia Historica. Historia Medieval, vol. 5 (1987), pp. 50 y ss.

${ }^{5}$ Estepa Díez, Carlos, "Formación y consolidación del feudalismo en Castilla y León", En torno al feudalismo hispánico. I Congreso de Estudios Medievales, Móstoles, 1987, pp. 223 y ss., y Las behetrías castellanas, I y II, Junta de Castilla y León, 2003, I, cap. 2.

${ }^{6}$ Oliva Herrer, Hipólito Rafael, "Memoria colectiva y acción política campesina: la behetrías de Campos hacia las Comunidades”, Edad Media. Revista de Historia, 4 (2001), pp. 63 y ss.

7 Martínez García, Luis, "Jurisdicción, propiedad y señorío en el espacio castellano del Camino de Santiago (ss. XI y XII)", Hispania. Revista Española de Historia, vol. LXVIII, núm. 228 (2008). Asumen que la benefactoría es un instrumento de subordinación y una forma de dependencia MínguEZ, José María, "Ruptura social e implantación del feudalismo en el noroeste peninsular", Studia Historica, Vol. III, 2 (1986), p. 29, PASTOR, Reyna, "Sobre la articulación de las formaciones económico-sociales: comunidades de aldea y señoríos en el norte de la Peninsula Ibérica (siglos X-XIII)", en BonnAssie, Pierre 
Los primitivos pactos de benefactoría, en suma, han sido comprendidos por los historiadores como a) formas de encomendación, b) formas de explotación de la reserva, c) formas de dependencia personal, y d) formas de servidumbre. A diferencia de estos criterios (aunque sin negarlos completamente), el vínculo de benefactoría será considerado aquí desde el concepto de modo de producción campesino propuesto por Chris Wickham ${ }^{8}$. Se plantea que las relaciones de benefactoría expresan prácticas sociales derivadas del modo de producción campesino, que se desarrollan en los intersticios de un espacio feudalizado, por lo cual adquieren progresivamente otros contenidos. El carácter inacabado de la expansión feudal en el XI se manifiesta en la pervivencia de usos tribales y en su gradual subordinación a la lógica aristocrática dominante en el área; el estudio de la benefactoría contribuye por ello a la comprensión del proceso por el cual la relación de explotación feudal y sus formas políticas conquistan espacios ajenos a su influencia mediante la transmutación de la práctica campesina y la alteración paulatina de su sentido original'. La reformulación de la práctica campesina, latente en las benefactorías castellano-leonesas del XI, culmina hacia principios del XII, etapa en que se verifica la transformación de los servicios prestados voluntariamente por los homines de benefactoria en rentas agrarias, $\mathrm{y}$ es plenamente visible desde comienzos del XI en algunos pactos del área galaicoportuguesa que implican la pérdida de la autonomía económica de los beneficiados.

El análisis se concentra en el vínculo entre benefactor y beneficiado, el cual se expresa en un conjunto de prácticas sociales (dotación de tierras, padrinazgo, mediación en disputas interfamiliares, elección de jefe, hospitalidad) propias de sociedades primitivas, cuyo contenido tiende a adaptarse a la lógica de la totalidad en que esas prácticas se inscriben. Asimismo se identifican elementos inherentes a la praxis campesina que facilitan la evolución señalada.

La práctica social, según surge de la documentación relativa a benefactorías, se estudiará en perspectiva comparada con la información que brindan las llamadas "sagas familiares" o sagas de los islandeses ${ }^{10}$. Se recurre a esta literatura con el fin de profundizar el análisis de aspectos del funcionamiento social que las sagas de

et al., Estructuras feudales y feudalismo en el mundo mediterráneo, Barcelona, 1984, p. 110, y PASTOR Díaz de Garayo, Ernesto, Castilla en el tránsito de la Antigüedad al feudalismo. Poblamiento, poder político y estructura social del Arlanza al Duero (siglos VII-XI), Junta de Castilla y León, 1996, p. 294, entre otros.

8 Wickнам, Chris, Framing the early Middle Ages. Europe and the Mediterranean 400-800, Oxford, 2005, pp. 535-550 y 358 y ss.

9 Carlos Astarita ha explicado la formación de relaciones feudales en el reino asturleonés a partir del ejercicio del poder político y la reformulación de antiguas costumbres mediante la intervención condal en la práctica campesina, Astarita, Carlos, "Prácticas del conde y formación del feudalismo. Siglos VIII al XI", Anales de la Universidad de Alicante. Historia Medieval, 14 (2003-2006). Aquí se retoma parcialmente este criterio, y se aplica al proceso de expansión de relaciones feudales sobre espacios libres durante el siglo XI.

${ }^{10}$ Sobre las sagas de Islandia como forma literaria y como relato verosímil, para la audiencia del XIII, de la historia de Islandia desde la colonización hasta la conversión al cristianismo vid. BYock, Jesse L., 'Saga Form, Oral Prehistory, and the Icelandic Social Context', New Literary History, vol. 16, Na 1, Oral and Written Traditions in the Middle Ages (Autumn, 1984), y Fentress, James, and Wickham, Chris, Social memory, Oxford-Cambridge, 1992, pp. 163-172. 
Islandia describen con gran riqueza de detalles, lo que contribuye a descubrir su alcance y significación.

\section{LA DOTACIÓN DE TIERRAS A CAMBIO DE SERVICIOS}

Una de las prácticas que expresa el vínculo entre benefactor y beneficiado es la dotación de tierras a cambio de servicios. La cesión de tierras por parte del benefactor aparece ampliamente en la documentación del siglo XI. Se trata de diplomas de donación o venta de solares y heredades, recogidos en la colección de Sahagún y de la catedral de León, en los cuales se explicita la capacidad de elegir señor por parte del que recibe las tierras ("ut vadas ad qualem dominum volueris, pergas cum ipso solare ad qualemcumque dominum volueris, qui tibi bene fecerit", etc. ${ }^{11}$. En casi todos los casos miembros de familias condales ceden tierras en régimen de benefactoría para obtener, mantener o retribuir un servicio (pro bono seruitio), probablemente -aunque no exclusivamente- un servicio militar.

El sentido de la voz benef ciar como sinónimo de dotar con tierras para el servicio militar aparece en el fuero de Castrojeriz del año 974, que exime de ir a la guerra a los caballeros que no hayan recibido una base material de sustentación, quienes deberán buscar señor que se las conceda -qui benefecerit illos $-{ }^{12}$. Este contenido se comprueba en algunos diplomas donde la expresión bene facere se equipara a la acción de otorgar un prestimonio: en 1086 Domingo Pérez dona a Esteban Cítiz un herrenal y dos solares, concediéndole licencia de servir a quien quisiera "qui tibi bene fecerit vel prestauerit"13, es decir, a quien lo beneficie o le otorgue un préstamo. Martínez Sopena ha interpretado que este tipo de fórmula indicaría que la cesión inicial de un lote-corvea se complementa con la cesión posterior de préstamos por parte de aquel a quien elija el cesionario ${ }^{14}$. Éste no parece ser el caso en los diplomas analizados, en los cuales se alude a la función militar con algún objeto simbólico. Martín Flaínez, por ejemplo, dona a Velite Cítiz un solar con fuero de benefectura et de benfectria; a la muerte del donante Velite o su descendencia podrán ir con quien quieran, "que bene fecerit et bene prestauerit"15. Velite, que llama domino meo a su benefactor Martín Flaínez, promete retribuir la donación con una espada, un gesto

${ }^{11}$ Herrero de la Fuente, Marta, Colección diplomática del monasterio de Sahagún (857-1230), II (1000-1073) y III (1073-1109), León, 1988; FernÁNDEZ FlóreZ, José Antonio, Colección diplomática del monasterio de Sahagún, IV (1110-1199), León, 1991 (en adelante, para ambas colecciones, Sahagún); Ruíz Asencio, J. M., Colección documental del Archivo de la Catedral de León (775-1230), III (986-1031), Madrid, 1987, y Ruiz Asencio, José Manuel, Colección documental del Archivo Catedral de León (775-1230), IV (1032-1109), León, 1990 (en adelante, para ambas colecciones, Archivo Catedral de León).

12 "Caballero de Castro, qui non tenuerit prestamo, non vadat in fonsado, nisi dederint ei espensam, et sarcano illo Merino et habeant segniorem, qui benefecerit illos", Fuero de Castrojeriz (974), MuÑoz y Romero, Tomás, Colección de Fueros municipales y cartas pueblas, Madrid, 1847, p. 38.

13 Sahagún, doc. 825 (1086).

${ }^{14}$ Martínez Sopena, "Parentesco y poder en León”, p. 52.

15 Sahagún, doc. 826 (1086). 
que evidencia que ambos comparten la condición de guerreros ${ }^{16}$. Se deduce que estas dotaciones comprometen al cesionario a la prestación de un servicio de armas antes que al cumplimiento de faenas agrícolas, y que el prestimonio en este contexto ha de entenderse como tenencia militar.

Las dotaciones pueden ser temporales, vitalicias o hereditarias. Las tierras que en 1095 recibe Pelayo Faíldiz de la condesa Ildonza pasarán a integrar el patrimonio del monasterio de Sahagún después de su muerte (la de Pelayo). En este caso la relación de benefactoría se limita a la vida del donatario, quien podrá servir al señor que quiera si su benefactor muere antes que él ${ }^{17}$. En un solo caso la cesión renueva el disfrute de la tenencia a los hijos del cesionario anterior, aunque el actual no podrá transmitir el bien, que a su muerte pasará a Sahagún ${ }^{18}$.

En otras escrituras las tierras cedidas son equiparadas a alodios. Según se lee en la donación del conde Alfonso Muñoz a Fernando Núñez éste y su descendencia podrán disponer plenamente de la heredad: "aveas, vindeas, dones, commutes tu et filiis tuis quo tivi queris" ${ }^{19}$; también podrán vender y donar los hijos de Pedro Pinólez, que reciben tierras "per bono seruicium et per bonam uoluntatem et per bonum amorem que habemus vobiscum" ${ }^{20}$. Fórmulas similares aparecen en otros casos: "et quicquid tibi de illa placuerit facere, facias: uendere, dare, tua uoluntate complere, in uita siue post mortem, tu et ex omni progenie tua" ${ }^{1}$; o bien "abeasque licentiam facendi ex eo quod tua extiterit uoluntas" ${ }^{22}$, etc. Se ha sugerido que esta terminología no expresa propiedad plena sino la constitución de un vínculo, el cual, aun cuando exista disposición sobre el bien, supone una contraprestación o alguna obligación para el cesionario; por otro lado este tipo de cesión, según la perspectiva antropológica, conlleva la presencia del donante en el objeto cedido, lo cual implica un condicionamiento para quien lo ha aceptado $^{23}$. Con independencia del estatuto de las tierras obtenidas, y de la heterogeneidad del conjunto de los que suscriben pactos de benefactoría, en algún caso se comprueba la condición de propietario alodial del beneficiado: el presbítero Gonzalo, que recibe una corte con la facultad de servir al

16 "Ego Beliti Citiz a uobis Martino Flayniz, domino meo, dauo uobis una espata ualente XX solidos de argento", ibidem.

17 "Ut seruias michi cum eo omnibus diebus mee; et post meo obitum seruias cui tu volueris cum eo; post mortem tuam, veniat ipso solare cum omnem suam hereditatem post partem Sancti Facundi", Sahagún, doc. 953 (1095)

${ }^{18}$ El hijo del conde Nuño Ermeíldiz dona una serie de divisas al monasterio de Sahagún excepto "uno solo solare que fuit de Sendina et dedimus illo a filio suo Citi Perez, ut uadat cum illo a quibus uolerit de heredes mei... post diem separationis sue anima a corpore sit stauilitum ipso solare post partem superius scripti monasterii Sancti Facundi”, Sahagún, doc. 549 (1051).

19 Sahagún, doc. 566 (1054).

20 "Et faciatis ex eo quicquid extiterit uestra uoluntas, uendere, donare; et habeatis ipsum solare confirmatum, uos et omnis posteritas uestra”, Sahagún, doc. 1252 (1133).

${ }^{21}$ Sahagún, doc. 1189 (1113).

${ }^{22}$ Sahagún, doc. 702 (1071).

${ }^{23}$ Morsel, Joseph, La aristocracia medieval. El dominio social en Occidente (siglos V-XV), Publicacions de la Universitat de Valencia, 2008, p. 207. 
señor que quiera ${ }^{24}$, ha vendido antes unos bienes que ha obtenido por compra y sobre los que no pesa ninguna obligación ${ }^{25}$.

En algunos diplomas las operaciones emulan el formato de las donaciones entre miembros de la aristocracia, donde la cesión de tierras es retribuida con un presente simbólico de alta estimación: Esteban Cilvánez, que recibe un solar, ofrece como confirmación de la carta un caballo valorado en 150 sueldos ${ }^{26}$; Pedro Giménez, que obtiene un solar con fuero de préstamo, obsequia un galgo ${ }^{27}$. Estos casos podrían indicar que los cesionarios pertenecen al círculo aristocrático que los beneficia, aunque veremos luego que esto debe matizarse; otros diplomas, por otro lado, los muestran como caballeros cuya condición de tales es precaria: el testamento de Monio Núñez, datado entre 1085 y 1115, incluye la donación de un solar a Martino Muñiz, quien podrá servir al señor que quiera; el testador dona también a Martino el caballo que este último venía usando, propiedad de Monio, lo que demuestra que los beneficiados eventualmente eran equipados por el patrono para el servicio militar ${ }^{28}$. Esta situación se explicita en algunos diplomas: en 1073 Juan Vermúdez dona a Domingo Álvarez, pro bono seruitio, un solar con su heredad, y además, un potro, para que sirva al donante hasta su muerte, después de la cual podrá vincularse a cualquier señor ${ }^{29}$. En otro caso el beneficiado, a quien se otorga un solar y una heredad con fuero de mare ad mare, recibe junto con la tierra un caballo, una mula, tres bueyes, veintidós ovejas y siete $\operatorname{cerdos}^{30}$. Estos bienes se describen como componentes de la unidad productiva ("quam ibidem ad prestandum est"), lo cual permite una aproximación a la entidad del conjunto de medios de producción en juego, que parece corresponder a una unidad doméstica de dimensiones modestas. Se deduce que nuestro beneficiado es un campesino a quien se facilitan medios de vida básicos y lo esencial del equipo militar, con el cual podrá prestar su apoyo a miembros diversos de la aristocracia ("ad rei", "ad conde", "ad infancone", "ad quale dono volueris").

La necesidad de obtener lealtades en el medio campesino se comprende en un contexto de competencia interseñorial, que a su vez se manifiesta en las dotaciones materiales para ganar adeptos. En 1063 Juliana Muñiz dona a Sesguto Escámez una heredad en la localidad de Santa Cruz, con plena libertad de elección de señor; Sesguto retribuye la donación con un caballo ${ }^{31}$. Al año siguiente Juliana, esta vez junto a su

${ }^{24}$ Sahagún, doc. 624 (1063).

25 "Ut uinderem uobis ego Gundisaluo presbiter et germana mea Geluira una corte de mea comparacione... ut de isto die de iuri nostro abstracto uestro sit tradito et faciatis de eo quod uestra extiterit uoluntas", Sahagún, doc. 578 (1056).

${ }^{26}$ Sahagún, doc. 702 (1071).

27 Sahagún, doc. 1198 (1117). Los beneficiados ofrecen caballos como confirmación de la carta de donación o venta en los documentos 634 (1063), 638 (1064), 702 (1071), 713 (1072), 719 (1073) у 720 (1073); espadas en los diplomas 826 (1086) y 887 (1092); en algún caso una mula, 795 (1081).

28 "Et tibi, Martino Munniz, dono uno solare, ubi tu volueris; et illum cauallum quem tenes de me, habeas solutum pro mea anima; pergasque cum ipso solare ad qualemcumque dominum uolueris", Sahagún, doc. 1173 (1085-1115).

29 "Et do tibi uno potro rodane ut seruias michi in illo dum dixero; et post obitum meum, uadas cum eo ubicumque uoleris", Sahagún, doc. 721 (1073).

${ }^{30}$ Archivo Catedral de León, doc. 1233 (1084).

${ }^{31}$ Sahagún, doc. 634 (1063). 
hermana Paterna, vuelve a dotar a Sesguto, por su buen servicio, con un solar en otro lugar ${ }^{32}$, lo que evidencia que la lealtad de Sesguto debió ser renovada, y que la dotación de tierras no asegura el apoyo sostenido de los beneficiados. Éstos, a su vez, aparecen en algunos casos sirviendo simultáneamente a señores diferentes: Rodrigo Miguélez, por ejemplo, recibe en 1073 un solar de Armentario Vélez con la facultad de acudir a cualquier señor; a cambio del solar ofrece un caballo rucio ${ }^{33}$; en el mismo año recibe de Pedro Vermúdez, pro bono seruicio, otro solar en la misma zona y en plena propiedad, esta vez a cambio de un caballo rosillo y un galgo ${ }^{34}$. Este solar tiene dimensiones muy modestas (lo que pueden labrar dos bueyes) ${ }^{35}$, lo cual sitúa a Rodrigo en el universo campesino de la aldea. En este nivel se manifiesta la competencia señorial por reclutar apoyos mediante dotaciones de bienes, las cuales deben mostrarse equivalentes a las concesiones que realizaron otros señores en la misma localidad: tal el caso de Elvira y su hijo Flaíno Fernández, que en 1071 otorgan a Esteban Cilvánez un solar en el lugar de Santa Cruz "similiter tamanio quomodo est ille" de Sesguto Examiz (el que recibió solares de Juliana Muñiz) ${ }^{36}$. El ejemplo también ilustra la coexistencia de vinculaciones variadas en una misma aldea.

La dotación de tierras a beneficiarios campesinos a cambio de servicios de diversa índole ha sido considerada por Wickham como una de las formas características de vinculación entre comunidades campesinas y aristócratas externos, cuya posición frente a jefes rivales en gran parte depende del apoyo de clientes libres, el cual puede obtenerse mediante concesiones materiales; la extensión de estos vínculos en el medio campesino y la existencia de un espectro amplio de potenciales alianzas expresa para el autor la incidencia política del campesinado en las redes de poder supralocales $^{37}$, un parámetro que retomaremos luego para evaluar el peso relativo de sectores campesinos en un contexto de predominio aristocrático.

Los sujetos que participan de estas relaciones, por último, podrían asemejarse en algunos casos a los milites de origen campesino que detecta Bonnassie en la Cataluña de mediados del XI, aldeanos poco sumisos que servían a varios señores a la vez sin asumir obligaciones relevantes con ninguno y sin integrarse plenamente al sistema feudovasallático; el autor los distingue de los milites castri comprometidos a la defensa de las fortalezas señoriales que acabarán integrados a las filas aristocráticas ${ }^{38}$.

Los historiadores han reconocido en las dotaciones materiales que retribuyen el servicio militar de patrocinados un antecedente de las concesiones beneficiales ${ }^{39}, \mathrm{y}$

${ }^{32}$ Sahagún, doc. 683 (1064).

33 Sahagún, doc. 719 (1073).

34 "Ut de isto die habeas licenciam faciendi de ipso solare et de ipsa hereditate quod tua extiterit uoluntas", Sahagún, doc. 720 (1073).

35 "Cum suas terras, ut habeat uno iugo de boves ad duas folias in aratura quod laborent", Sahagún, doc. 720 (1073).

${ }^{36}$ Sahagún, doc. 702 (1071).

37 WickHam, Framing, pp. 391 y ss.

${ }_{38}$ Bonnassie, Pierre, Cataluña mil años atrás (siglos X-XI), Barcelona, 1988, pp. 388-389.

39 Dopsch, Alfons, Fundamentos económicos y sociales de la cultura eur opea (de César a Carlomagno), Buenos Aires, 1951, pp. 386 y ss., defiende que las relaciones de fidelidad personal y la retribución material del servicio son instituciones que aparecen asociadas en la compañía germánica y en las encomendaciones tardorromanas, por lo que la unión de vasallaje y beneficio no representa una nove- 
asimismo han observado la conversión directa de vínculos clientelares en relaciones feudovasalláticas ${ }^{40}$; la incorporación de sectores rurales a las mesnadas señoriales se ha relacionado con la reorganización y adaptación de la aristocracia a los requisitos de estructuración del señorío banal ${ }^{41}$. Tal vez la relación de benefactoría pudo inscribirse en algunos casos en este proceso de reformulación y ampliación de la aristocracia, que comprendería la transformación de clientes en vasallos, aunque veremos también que el conjunto relativamente indiferenciado de beneficiados (personajes destacados, modestos caballeros y campesinos eventualmente equipados para la guerra) tiende a escindirse en la centuria siguiente en milites y labradores; los primeros probablemente quedarán integrados en la "feudalidad"; los segundos sujetos a relaciones de explotación feudales.

\section{LAS RELACIONES DE CRIANZA O PADRINAZGO}

La crianza de los hijos de los benefactores es otro de los servicios que motiva las donaciones y que constituye en muchos casos el contenido principal de la relación social que expresa el vínculo de benefactoría. En 1102 Citi Álvarez dona a Juan Mániz un solar con su heredad, el cual había recibido del conde Pedro Ansúrez como retribución por haber criado a sus hijos ${ }^{42}$. Citi concede el solar con el mismo fuero que le había dado en su momento el conde, estableciendo que el cesionario y sus descendientes podrán servir con estos bienes a quien quieran ${ }^{43}$. A partir de este ejemplo algunos autores han considerado que el vínculo de crianza se encuadra en la relación de vasallaje, que comprendería la instrucción militar de los hijos del señor por parte de sus vasallos ${ }^{44}$. El padrinazgo y el vasallaje, sin embargo, se presentan como vínculos diferenciados e involucran a distintos sectores sociales, según veremos a continuación.

dad del periodo carolingio, aunque sí su difusión, que el autor relaciona con la disponibilidad de tierras por parte de la aristocracia. Desde otro ángulo Stephen White afirma que en la medida en que el feudo retribuye un servicio ya prestado, lo cual constata en las concesiones beneficiales del XI, las relaciones feudovasalláticas no difieren totalmente del patrocinio de periodos anteriores, encontrándose ambas prácticas animadas de cierto "espíritu de largueza" que cuestionaría la consideración del vasallaje como un vínculo contractual llamado a asegurar un servicio futuro. Al igual que Dopsch, White rechaza la idea de un momento histórico decisivo caracterizado por la unión de vasallaje y feudo, subrayando en cambio los elementos de continuidad, White, Stephen, "Service for Fiefs or Fiefs for Service: The Politics of Reciprocity", en Algazi, Gadi, Groebner, Valentin and Jussen, Bernhard, Negotiating the gift. Pre-Modern Figurations of Exchange, Göttingen, 2003, p. 98.

${ }^{40}$ Morsel, La aristocracia medieval, p. 68.

${ }^{41}$ Morsel, La aristocracia medieval, pp. 149-150.

42 "Et habui ego Citi Albariz ipso solare de incartacione de comite Pedro Ansuriz et de sua mulier, propter filios eorum que ego nutriui”, Sahagún, doc. 1086 (1102).

${ }_{43}$ "Facio tibi carta per tale foro quomodo ille comes michi fecit et vadas cum eo ubi volueris, tu et filius tuus et omnis progenie tua", Ibidem.

44 Barton, Simon, The aristocracy in twelfth-century León and Castile , Cambridge University Press, 1997, p. 47. También presenta el padrinazgo como una práctica aristocrática dirigida a consolidar vínculos de camaradería Morsel, La aristocracia medieval, pp. 83-84. 
En 1064 la condesa Mumadonna cede dos solares y tres tierras a Velite Álvarez, sirviente de la familia ("tibi criado nostro"), para que las cultive ${ }^{45}$. Cuatro años más tarde dos diplomas muestran las tratativas del hijo de Mumadonna, el conde Pedro Muñoz, para dotar con tierras a Velite; estos diplomas indican que Velite, además de ser sirviente de la familia, se encuentra vinculado al conde por una relación de crianza. Para retribuir los servicios de Velite Pedro Muñoz solicita tierras a Alfonso VI, un hecho que podría sugerir una situación de relativa debilidad patrimonial por parte de la aristocracia, y que a la vez muestra la importancia que sus miembros conceden a las vinculaciones de tipo clientelar, las cuales comprenden la dotación de tierras a criados. Alfonso VI cede al conde, a quien llama $f$ deli meo, la tierra que este último había pedido para Velite, amo tuo según lo denomina el rey, lo que señala que Velite ha criado al conde ${ }^{46}$, y que este último apela al vínculo vasallático con el rey para construir una relación de benefactoría con su ayo, a quien evidentemente quiere promocionar. Una vez obtenida la tierra (una corte con su heredad) Pedro Muñoz la cede a Velite, con la facultad de elegir señor libremente, aunque si Velite muere sin descendencia la tierra pasará al monasterio de Sahagún, para la salvación de su alma, la de su benefactor y la del monarca que facilitó la tierra ${ }^{47}$. El vínculo vasallático entre el conde y el rey no se confunde con la relación de crianza; en todo caso condiciona la relación de benefactoría entre el conde y su ayo: permite al benefactor la dotación de tierras e impone al beneficiado su transferencia post mortem a otro sector de la aristocracia.

El vínculo de crianza, propio de la benefactoría, es uno de los aspectos que reaparece en la documentación de behetrías. Isabel Alfonso ha destacado la vigencia del padrinazgo en los siglos XIII y XIV; mediante la crianza de los hijos de los hidalgos los campesinos de behetría obtenían beneficios diversos y el privilegio de exención tributaria ${ }^{48}$. Esto se observa en un documento de 1226, donde la condición misma de behetría se asocia a la práctica de criar a los hijos de los hidalgos. Se trata de un pleito entre la iglesia de Lugo y ciertos sujetos que se niegan a satisfacer los servicios que pagaban los habitantes del lugar, argumentando que eran hombres de behetría,

45 "Ed damus cum eos foro que prendas in nostra diuisa et ares quantum potueris", Sahagún, doc. 638 (1064).

46 "Do tibi ista corte quam michi petisti pro ad amo tuo Velliti Albaret", Sahagún, doc. 675 (1068).

47 "Ut vadas cum illa curte et cum ipsa hereditate a Kastella vel a Gallecia vel in ista terra, a quales domnos volueris in uita tua. Et si contingerit si absque liberos fueris sit conconsessa (sic) ipsa hereditate a parte Sactorum Facundi et Primitibi, pro remedium anime tue", Sahagún, doc. 676 (1068). En la donación de Alfonso VI al conde se establece que "post mortem vero suam (de Velite) veniat ipso solare, cum tota hereditate, sicut fuerit inuenta in die mortis eius, post partem Sancti Facundi pro remedio animarum nostrarum", Sahagún, doc. 675 (1068). Cuarenta años después se efectúa la donación a Sahagún: "Et ipso solare dedit cum rex Adefonsus, cum sua hereditate, a Pedro Monniz; et Pedro Monniz fecit cartula a suo aio Uellito Albariz, sub tale pactu, ut post mortem de Vellito Albariz ipso solare cum tota sua hereditate remaneret post partem Sanct Facundi pro anima Petro Monniz et de ipso Vellito Albariz" Sahagún, doc. 1155 (1107).

48 Alfonso Antón, Isabel, "Conflictos en las behetrías", en Estepa Díez, Carlos y Jular PérezAlfaro, Cristina (eds.), Los señoríos de behetría, Madrid, 2002, pp. 251-252. 
que alimentaban a los hijos de los caballeros y que elegían señor libremente ${ }^{49}$. Aparece también una referencia en el Becerro de las Behetrías de 1352: en relación a una renta, el fumo, todos pagan excepto el que tiene potro o es amo de los escuderos ${ }^{50}$. La difusión de esta práctica en la época de los diplomas de Sahagún se confirma en un privilegio de Alfonso VI al monasterio de Samos que prohíbe a los milites tener vasallos "per amatiatum sive criandum" en el coto del monasterio, sancionando asimismo a los habitantes del lugar que criaran a los hijos de aquéllos, lo que sugiere que por esta vía los labradores se sustraían de las obligaciones hacia el $\mathrm{abad}^{51}$, y que habitualmente hidalgos y campesinos establecían este tipo de tratos, que el monasterio reprime como parte del proceso de imposición del señorío. Del ejemplo se deduce que el padrinazgo, frente a la relación de explotación, implica un vínculo de distinta naturaleza, aun cuando una de las partes sea referida formalmente con el mismo vocablo que señala al señor feudal ("qui se amo fecerit vel qui se in alium dominum transtulerit, ad dominum monasterii reducat").

La documentación de Sahagún ofrece también testimonios donde el que recibe tierras ha sido criado por el señor. El caso de Diego Pátriz ejemplifica esta situación: en el año 1059 recibe de Tello Gutiérrez, hijo del conde Gutier Alfonso, una heredad "propter creacionem quam sub Deo creaui te et propter seruicium bono", lo cual parece indicar que Diego Pátriz se habría criado en la casa de Tello ${ }^{52}$. La donación establece que Diego deberá servir con el solar a su padrino Tello hasta la muerte de este último, después de la cual podrá acudir a quien quiera. A diferencia de otros diplomas, en éste se especifica claramente que el beneficiado no podrá servir a otro señor mientras viva Tello ("non permitto te servire cum illo alio domno"). Más de treinta años después, tal vez cansado del servicio que ha brindado y para salvar su alma ("non solum pro remedio anima mee, verum etiam et ut ego sim liber in omnia vita mea de omni servicio humano"), Diego Pátriz dona el solar al monasterio de Sahagún, por lo cual sus hijos, que conservan el usufructo, se verán sometidos a explotación señorial. Pátriz, que considera muy estrictas las obligaciones que suele imponer el abad - una perspectiva que lo sitúa por fuera de la relación de dependencia- solicita en la carta de donación un trato diferencial para sus hijos: propone que aquéllos no tributen al monasterio más de 12 días de prestaciones de trabajo, y que en caso de tener caballo sirvan como caballeros ${ }^{53}$, lo que sugiere que éste debió ser el servicio que Pátriz brindaba a Tello, y que no ha podido transmitir esta condición a sus hijos. Esta información aleja a Pátriz de la figura del "vasallo de criazón", que

49 "Et dixit dictus advocatus, quod erant de bene[fetria] de mare usque ad mare et quod nutriebant filios et filias militum terre et quod erant vassalli liberi illius cuius volebant [in] omnibus", HinoJosA, Eduardo de, Documentos para la historia de las instituciones de León y Castilla (siglos X-XIII), Madrid, 1919, LXXVIII, p. 132.

${ }^{50}$ Martínez Díez, Gonzalo, Libro Becerro de las behetrías, I y II, León, 1981, I, 3, 24.

51 "Et si aliquis filius militis ibi nutritor vel aliquis ibi se posuit sub alio domino nisi sub domino samonensis, mando isti homini meo, quod filium militis, qui in cautos samonensis nutritor, foras de cautos eiciat", Hinojosa, Documentos, LVII (1195), p. 96.

52 Sahagún, doc. 606 (1059).

53 "Et filii mei non subiugati tam stricti sint in servicio sicut ceteri, sed ut tantummodo ponant XIIm dies in anno ad servicium domni abbatis; quos si habuerit kavallos serviant sicut kavallarii”, Sahagún, doc. 909 (1093). 
se identifica con infanzones, situándolo en cambio en el difuso conjunto de campesinos y caballeros villanos, y también en la tendencia hacia la pérdida de autonomía económica de muchos de sus miembros.

Esta evidencia, sumada a la anterior, señala la existencia de vinculaciones recíprocas entre familias campesinas y aristocráticas, en las cuales tanto unos como otros actuaban como padrinos. Esto se confirma en documentación del xII: "multi eorum erant nutricii et alumpni militum... et nutriebant filios et filias eorum" ${ }^{54}$. Estos vínculos, según hemos visto, se formalizan mediante pactos de benefactoría.

Los especialistas han estudiado el vínculo de crianza o padrinazgo, referido genéricamente como fosterage, al cual consideran una forma de alianza clientelar orientada al reclutamiento de apoyos en sociedades primitivas y un recurso político fundamental en la lucha entre facciones o clanes rivales. En la Irlanda medieval la entrega de niños a subordinados se complementa con la cesión de tierras, a cambio de la cual los dadores obtienen de sus clientes lealtad política, servicios militares y prestaciones de hospitalidad ${ }^{55}$. En términos generales el vínculo tiene carácter asimétrico (quienes toman niños para crianza se consideran inferiores), de hecho la relación de crianza entre no emparentados se define como una forma de alianza política entre familias de distinto rango social. No obstante, el padrinazgo se establece también entre iguales ${ }^{56}$.

Las sagas islandesas ofrecen numerosos ejemplos del vínculo de crianza. La práctica de criar a los hijos de otro suele sellar acuerdos entre familias, alianzas matrimoniales o propuestas de reconciliación. Olaf el pavo real, héroe de la saga de Laxdæla, ofrece criar al hijo de su hermano Thorleik como medio de zanjar las diferencias entre ambos. La oferta se produce luego de un multitudinario banquete que ha acrecentado la reputación y popularidad de Olaf; el momento que éste elige para ofrecerse como padrino confirma la funcionalidad del vínculo de crianza como herramienta de negociación ${ }^{57}$. Otro caso que ejemplifica la relación de crianza es el de Hoskuld, uno de los personajes centrales de la saga de $\mathrm{Njal}$, criado por este último. Hoskuld es un niño cuando su padre Thrain es asesinado por Skarp-Hedin, uno de los hijos de Njal (trataremos luego los motivos de este asesinato). Njal, tras pagar la compensación por la muerte de Thrain, mantiene con el hermano del muerto una larga conversación, después de la cual se acerca al pequeño Hoskuld, le regala su anillo y le propone llevarlo a vivir a su casa. Hoskuld acepta el anillo y el padrinazgo de Njal, que considera un gesto de generosidad ${ }^{58}$. Njal, destacado jurista de Islandia, educa a Hoskuld hasta convertirlo en goði. La crianza de hijos ajenos se presenta en este caso como una forma de complementar el wergeld y consolidar la reconciliación entre familias; Hoskuld promete no vengar a su padre, por el cual se ha pagado plena

54 Citado por Alfonso, "Conflictos en las behetrías", p. 250.

55 Parkes, Peter, "Celtic Fosterage. Adoptive Kinship and Clientage in Northwest Europe”, Society for Comparative Study of Society and History (2006), p. 363.

56 PARKes, Peter, "Fostering Fealty: A Comparative Analysis of Tributary Allegiances of Adoptive Kinship," Comparative Studies in Society and History, vol. 45, Nª 4 (oct. 2003), p. 753 y ss.

${ }^{57}$ Laxdcela saga, ed. Magnus Magnusson and Hermann Pálsson, London, 1969, 27.

58 Njal's saga, ed. Magnus Magnusson and Hermann Pálsson, London, 1960, 94. 
compensación. (Esta actitud expresa valores distintos a los que portan los héroes de la saga, que en general consideran deshonroso renunciar a la venganza de sangre ${ }^{59}$.)

Los especialistas han observado que la práctica de criar a los hijos de otro, a diferencia de la adopción, no implica que aquéllos hereden los bienes de quien los ha criado (heredan los bienes de los padres biológicos); sin embargo, frecuentemente son dotados con tierras; Njal compra tierras para instalar a Hoskuld cuando éste se casa. No obstante, aunque los apadrinados no gozan los mismos privilegios que los hijos biológicos, comparten con éstos el compromiso de defender el honor de la familia que los ha criado, lo cual generalmente implica asumir el compromiso de la venganza de sangre ${ }^{60}$. En el caso de Hoskuld, la oportunidad de actuar ante la deshonra de la familia adoptiva se presenta cuando un hijo natural de su padrino Njal es asesinado por tres hombres emparentados con Thrain. Skarp-Hedin, el hijo de Njal, no concibe otra salida más que la venganza directa, y asesina a dos de los hombres, pero el tercero, que logra escapar, pide un acuerdo de reconciliación, y con la intermediación de Hoskuld, que ya es el goði más famoso del distrito, lo consigue: Njal acuerda el pago de compensación por la muerte de su hijo. Skarp-Hedin nunca perdonará a Hoskuld el haber intercedido a favor de un enemigo de la familia: este rencor secreto está detrás de los acontecimientos en apariencia inexplicables que tiempo después conducen al asesinato del pacífico Hoskuld a manos de Skarp-Hedin. Aun cuando la muerte de Hoskuld, a diferencia de otras muertes, se presenta en la saga como un hecho lamentable y trágico, no deja de ser una expresión del funcionamiento social: Hoskuld ha incumplido su deber hacia la familia que lo ha criado.

La saga de Njal proporciona también ejemplos en los que miembros de las familias más notables de Islandia son criados por gentes de condición inferior e incluso por sirvientes. Hallgerd, casada en terceras nupcias con Gunnar, el héroe de la saga, y miembro de una de las familias más prestigiosas de Islandia, ha sido criada por Thjostolf, un oscuro guerrero que presta a Hallgerd el servicio de matar a sus dos primeros maridos ${ }^{61}$. Skarp-Hedin, el ya mencionado hijo de Njal, ha sido criado por Thord, hijo de un liberto y sirviente de la familia. Thord aparece al comienzo de la saga, involucrado en una disputa interfamiliar de su apadrinado Skarp-Hedin. Cuando es emboscado por sus asesinos (a quienes acompaña Thrain, el padre de Hoskuld, que observa la escena), éstos asumen que Thord ha de ser tan buen guerrero como Skarp-Hedin, ya que, según le comentan, "un cuarto de lo que uno es viene del padrino"; Thord replica, con idéntica lógica: "Skarp-Hedin me vengará"

${ }^{59}$ Se ha interpretado que la introducción de otros valores por parte de algunos personajes se asocia a la difusión del cristianismo, Magnusson, Magnus, Njal's saga, introduction; Fox, Denton, "Njáls Saga and the Western Literary Tradition", Comparative Literature, Vol. 15, № 4 (Autumn 1963), pp. 289-310. Sobre la oposición entre concepciones paganas y cristianas en las sagas de Islandia vid. ANDERSSON, Theodore M., "The displacement of the heroic ideal in the family sagas", Speculum, vol. 45, $\mathrm{N}^{\mathrm{o}}$ 4, (Oct., 1970), pp. 575-593.

${ }^{60}$ Rose, H. A., "Fosterage in Brittany and Iceland", Folklore, Vol. 37, No 4 (Dec. 31, 1926), pp. 398-399. Expone una extensa bibliografía sobre el tema en un conjunto variado de sociedades primitivas PARKes, "Fostering Fealty", pp. 741-782.

${ }^{61}$ Njal's saga, 11, 17.

${ }^{62}$ Sigmund said to him, 'Give yourself up, for now it is time for you to die.' 'Certainly not,' said Thord. 'Come and fight me in single combat.' 'Certainly not,' said Sigmund. 'We shall make use of our 
está implícito el mecanismo y la sustancia del don y el contradón: Skarp-Hedin retribuirá el don que ha recibido de Thord vengando su muerte.

Marcel Mauss ha establecido que el acto de aceptar un regalo trae consigo la obligación de devolverlo, por lo que el intercambio de dones sólo en apariencia es una relación voluntaria. El carácter compulsivo del vínculo se explica, según Mauss, por las cualidades atribuidas al don: éste contiene la esencia espiritual del dador, lo que implica la presencia permanente de este último en el objeto de intercambio, que es lo que vuelve ineludible su retribución -o peligrosa su no retribución- forzándolo a circular ${ }^{63}$. Mauss ha destacado este aspecto del intercambio de dones, que se manifiesta, en el nivel del lenguaje, en la evolución divergente del vocablo gift (regalo/ veneno ${ }^{64}$. En los mismos términos puede comprenderse el padrinazgo, un vínculo no exento de cualidades mágicas que obligan a la retribución del don, según se ha visto en el diálogo entre Thord y sus asesinos. La asimilación entre el padrinazgo y el intercambio de dones queda también sugerida cuando Hoskuld acepta el regalo y la protección de Njal como gestos de una misma naturaleza; Hoskuld no retribuye adecuadamente el presente que ha aceptado y por este motivo acaba muerto. En el caso de Skarp-Hedin y su padrino Thord, aun cuando Thord es un sirviente, su muerte, a diferencia de la de otros sirvientes involucrados en disputas de sus amos, por la que éstos pagan compensación, compromete personalmente a Skarp-Hedin, que no obstante haber obtenido doble compensación por Thord asume el deber de la venganza de sangre, con lo cual observa adecuadamente las reglas de su sociedad. En respuesta a unos insultos que llegan a sus oídos por medio de unas mendigas Skarp-Hedin asesina al partícipe directo de la muerte de Thord; ciertos comentarios sarcásticos y el ruido del hacha golpeando en un tabique anuncian sus planes. Veinte años después, a raíz de una afrenta sufrida en Noruega Skarp-Hedin se dispone a matar a Thrain; la repetición de los mismos detalles circunstanciales (los insultos, las mendigas, el ruido del hacha, los comentarios sarcásticos) nos revela los verdaderos motivos de Skarp-Hedin, que no ha olvidado la participación de Thrain como espectador en el asesinato de Thord, la persona que lo ha criado. En una escena en la que se despliegan al máximo sus cualidades de guerrero (se desliza por el hielo a toda velocidad, hacha en mano) Skarp-Hedin mata a Thrain y guarda su mandíbula como trofeo, que sacará a relucir más de diez años después, mientras libra su batalla final, antes de

advantage in numbers. It's not surprising that Skarp-Hedin is so formidable, since the saying goes that one-fourth comes from the foster-father.' 'You shall see the full force of that', said Thord, 'for SkarpHedin will avenge me', Njal's saga, 42.

${ }^{63}$ Mauss, Marcel, The Gift. Forms and Functions of Exchange in Archaic Societies, Glencoe, Illinois, 1954, pp. 61-62; MAuss, Marcel: Sociología y antropología, Madrid, 1991, pp 166-169. Esta explicación ha sido criticada por Godelier, Maurice, "Acerca de las cosas que se dan, de las cosas que se venden y de las que no hay que vender ni dar sino que hay que guardar. Una reevaluación crítica del ensayo sobre el don de Marcel Mauss", Hispania, LX/1, num. 204 (2000), también por SahLins, Marshall, Stone Age Economics, London 1984, cap. 4: The spirit of the gift, y por Wagner-Hasel, Beate, "Egoistic Exchange and Altruistic Gift. On the Roots of Marcel MAuss's Theory of the Gift", en Negotiating the gift, entre otros. La considera en cambio válida GurIÉvicH, Aron, Las categorias de la cultura medieval, Madrid, 1990, pp. 251-252.

${ }^{64}$ Mauss, Marcel, "Gift-gift", en Sociedad y ciencias sociales, Obras III, Barcelona, 1972, pp. 44-48. 
morir en el incendio de la casa de $\mathrm{Njal}^{65}$. Este detalle descubre la importancia de la muerte de Thord en la estructura narrativa de la saga (la muerte de Thord involucra a Skarp-Hedin en una disputa familiar que culminará más de treinta años después con el incendio de la granja de Njal, provocado por los vengadores de Hoskuld), lo que atestigua la jerarquía del vínculo de crianza en sociedades campesinas y su significación como práctica basada en el intercambio de dones.

El sentido de los lazos de crianza según se presenta en las sagas islandesas contribuye a la comprensión de las relaciones de benefactoría como derivación de prácticas campesinas, y a la consideración del padrinazgo como un vínculo de carácter indisoluble, lo cual favorece la consolidación de nexos más estables. Esta perspectiva podría explicar la perdurabilidad de la relación en algunos pactos de benefactoría, un aspecto que implica contradicción con la facultad teórica de modificar lealtades. Tal el caso de Diego Pátriz, que sirve a su benefactor Tello durante toda su vida; Pátriz se encuentra doblemente comprometido con Tello: por el solar que recibe y por el vínculo que contrae al haber sido criado en su casa, un vínculo de lealtad familiar que lo obliga a asumir como propias las enemistades de Tello y a permanecer bajo su servicio. Este doble compromiso se concreta en las prestaciones que Diego brinda a su padrino Tello durante más de treinta años, a las que se refiere como servicio humano, y que distingue del tributo que se paga al abad de Sahagún, al cual considera una forma de subiectio ("et filii mei non subiugati tam stricti sint in servicio sicut ceteri").

Según la literatura citada sobre sociedades celtas, la forma prototípica de la relación de padrinazgo es la cesión de tierras a subordinados con funciones de crianza, lo cual concuerda con los restantes casos que describen los diplomas de Sahagún, donde los que reciben tierras han criado a miembros de familias condales.

Por último, la participación de sirvientes en la relación de crianza, y la especial estimación que éstos gozan por parte de sus señores, según se ha visto en la saga de Njal, nos ayuda a comprender la dotación de tierras a collazos y criados con quienes la aristocracia establece vínculos de benefactoría. En el caso del conde Pedro Muñoz y su padrino Velite Álvarez, el sirviente que lo ha criado, la dotación de tierras por intermedio de Alfonso VI podría entenderse como retribución por parte del conde del don que ha recibido de Velite. En iguales términos puede comprenderse la dotación a collazos: en 1092 Pelayo Vermúdez dona a su collazo Vela Velázquez un solar con fuero de préstamo, con el cual podrá servir a quien quiera; Vela retribuye la donación con una espada valorada en 50 sueldos de plata, de lo cual se puede deducir que cumple servicios militares. El diploma subraya la relación de lealtad entre el collazo y el donante como motivo de la cesión ("pro que eretis meos collaços con fide et veritatem") ${ }^{66}$, lo que podría comprenderse como expresión de un vínculo clientelar semejante al padrinazgo. Estepa Díez ha propuesto que la referencia a collazos, en este contexto, podría responder al sentido primitivo de la voz collacteus, relacionado con el parentesco artificial ${ }^{67}$. Este criterio confirmaría que Vela, al igual que otros

${ }^{65}$ Njal's saga, 92.

${ }^{66}$ Sahagún, doc. 887 (1092).

${ }^{67}$ Estepa Díez, Las behetrías castellanas, I, p. 52. Según la interpretación del autor tanto Velite Álvarez como Vela Velázquez (y muchos otros que obsequian objetos de valor) serían en realidad mi- 
collazos mencionados, pudo estar relacionado con el benefactor por un vínculo de crianza.

La promoción a la condición libre de sirvientes con funciones de crianza es un dato corriente: en 1155 la condesa Elvira Velázquiz concede ingenuidad a la familia que la crió, en condiciones que remiten al vínculo de benefactoría, por cuanto los nuevos ingenuos podrán buscar libremente quien los proteja y beneficie ${ }^{68}$. El documento confirma también que la relación de benefactoría no tiene en principio carácter explotador, lo cual se explicita en la carta de ingenuidad: "a nullo homine obsequium reddant" ${ }^{69}$.

El tipo de relación que establecen las familias vinculadas por lazos de padrinazgo explica también que los homines de benefactoria resulten implicados en las disputas de sus señores. Esta circunstancia es materia de la normativa en el siglo XII: un decreto de Alfonso IX prohíbe prendar a aquéllos por deudas o enemistad que el interesado pudiera tener con los benefactores de tales hombres, a menos que los beneficiados estuvieran armados con lanzas ${ }^{70}$; se deduce que la prestación militar era corriente entre los beneficiados, aun cuando no estuvieran plenamente equipados, y que quedaban expuestos a las agresiones de los enemigos de su señor. La regulación de la actuación señorial frente a los beneficiados de otros señores, sin embargo, desplaza el problema de la implicación de los homines de benefactoria de la esfera del conflicto interfamiliar, que los involucra en las contiendas de sus líderes, a la esfera del conflicto interseñorial, que tiene a los clientes de señores rivales como objeto de disputa.

Este desplazamiento, expresivo de los mecanismos de la expansión feudal, no supone el abandono total de la práctica del padrinazgo, que aparece asociada a la lucha de bandos y a los conflictos internobiliarios de los señoríos de behetría del siglo $\mathrm{xv}$, de los cuales participan los moradores del lugar. La vigencia relativa del padrinazgo se deduce de una ordenanza de Becerril de Campos que exhorta a los vecinos a defender a los regidores y al comendero que gobierna la behetría frente a la intromisión de otros poderes; la ordenanza establece que en caso de que algún vecino perdiera la vida en estas circunstancias "que le crien el conçejo los fijos sy fueren pequeños" ${ }^{\prime \prime}$. Este ejemplo tardío atestigua la supervivencia residual de prácticas campesinas despojadas de la sustancia, donde la implicación de los vecinos en las disputas de sus jefes ya no expresa un vínculo de reciprocidad sino el ejercicio, por parte del señor, del dominio político sobre la persona de los moradores, que los obliga a combatir en las filas del magnate que dirime el señorío sobre el lugar.

lites. Esto es difícil de admitir en el caso de Velite Álvarez, a quien le exigen prestaciones de trabajo (vid. supra nota 44).

68 "Et dedit mihi illa comitesa dona Gelvira de quam fuit criatione, facio vobis cartam ingenuitatis et libertatis... ut redeunde, vivendi, laremque fovendi vitam vestram ubi volueritis", MuÑoz y Romero, Colección de fueros municipales, p. 162.

${ }^{69}$ Ibidem.

70 "Quod nullus pignoret benefactoriam pro debito vel inimicitia domine benefactorie, nisi ipse beneficiatus fuerit lancearius", Hinojosa, Documentos, XC (1188-1230), p. 148.

71 Oliva Herrer, Hipólito Rafael, Ordenanzas de Becerril de Campos (circa 1492). Transcripción y estudio, Institución Tello Téllez de Meneses, CECEL-CESIC, Diputación de Palencia, 2003, p. 201. 


\section{LA MEDIACIÓN EN CONFLICTOS INTERFAMILIARES Y LA ACTUACIÓN DE LOS BENEFACTORES EN LA ASAMBLEA}

Los benefactores aparecen también actuando como mediadores en disputas familiares. Esta función se atestigua en algunos documentos del área de Galicia y Portugal. En el año 1008 dos hermanos, Adosinda y Argerigo, ceden al presbítero Evenando la mitad de una heredad familiar ${ }^{72}$. El acto se presenta en el documento como una venta; el presbítero retribuye la tierra con ganado y alimentos ${ }^{73}$. El motivo de la cesión es la ayuda que el presbítero ha brindado actuando como mediador ante el esposo de Adosinda, a quien ésta ha traicionado, $\mathrm{y}$ tal vez ante la autoridad superior que percibe la multa por adulterio, de la cual aparentemente los hermanos han pagado sólo una parte ${ }^{74}$. El presbítero intercede ante el marido de Adosinda, reúne a los representantes de las dos familias en su propia casa, los aconseja y consigue la reconciliación entre las partes. Esta actuación es lo que define la relación de benefactoría, según se explicita en el documento: "et favolastis pro me ad meo marito virterla et dimisit mici illa merze et rezebit me pro sua muliere et consudunasti nos todos tres in tua kasa ad tua bemfeitoria".

El rol de los líderes locales como mediadores, arbitradores y peacemakers ha sido destacado por los estudiosos de las sagas islandesas ${ }^{75}$. Su misión es obtener la reconciliación entre las partes, complementaria o alternativa a la resolución judicial del caso. Comúnmente los mediadores, que operan en favor de una de las partes, interceden para que la otra acepte un acuerdo de reconciliación; la negociación en algunos casos incluye ofertas de amistad, alianzas matrimoniales o vínculos de crianza, lo cual involucra a los mediadores en las redes sociales locales y pone de manifiesto la importancia de su rango social para la resolución del conflicto. La actuación de los jefes locales y juristas destacados como mediadores en conflictos interfamiliares dentro y fuera de la asamblea es uno de los contenidos de la relación goðar-boendr (la relación entre los jefes locales y los hombres libres adscriptos a sus jefaturas), y una de las formas en que se manifiesta su poder de función. El éxito en las causas judiciales, a su vez, depende en gran parte de los apoyos reunidos, es decir, del número de hombres que el goði pueda llevar a la asamblea en favor de la causa que defiende, lo cual se encuentra en relación directa con su reputación como jurista o mediador exitoso.

William Ian Miller analiza un ejemplo interesante que proporciona la saga de Eyrbyggja, donde puede verse otro aspecto de la intervención de terceros en las disputas familiares: la cesión de tierras para retribuir los servicios de mediación. En

72 "Quanto inde tenemus in nostro iure qum mater nostra goda et virum suo trastemiro... nos tivi inde rovoramus medietate integra", Portugaliae Monumenta Historica. Diplomata et chartae , CCII (1008), p. 124.

73 "Et dedisti nobis adduc in pretio II boves et III modios de zivario et IIas cabras et uno carnario tanto nobis bene complacuit", Ibidem.

74 "Et damus tibi ea pro occasione que abenit ad ipsa adosinda et in suo peccato devenit a tradictione et abuit pro me a dare CL solidos et dedit inde illos L ad uilifonso mumdinizi", Ibidem.

${ }^{75}$ Miller, William Ian, "Avoiding Legal Judgment: The Submission of Disputes to Arbitration in Medieval Iceland”, The American Journal of Legal History, Vol. 28, № 2, (Apr., 1984), pp. 95-134. 
este caso los litigantes no desean un acuerdo de reconciliación sino ganar el caso en la asamblea $-\mathrm{O}$ arribar a un acuerdo en esa instancia ${ }^{76}$. Thorolf y Ulfar son vecinos en permanente conflicto. Ante las acciones hostiles de Thorolf, su hijo Arnkel, que es un goði prestigioso, intenta siempre compensar a Ulfar. Thorolf envía esclavos a incendiar la casa de Ulfar; Arnkel los descubre y los mata. Por la protección de Arnkel (que privilegia su jefatura por sobre el parentesco), Ulfar le transfiere su propiedad. Thorolf pretende compensación por sus esclavos muertos; Arnkel se niega a pagarla; Thorolf decide llevar su caso a los tribunales, para lo cual necesita un especialista de igual o mayor prestigio que Arnkel. Arnkel es uno de los goðar del distrito, a quien debería acudir Thorolf, quien, haciendo uso de sus libertades, cambia de jefe y acude a Snorri el goði para que presente su caso en la asamblea. Snorri en principio no acepta, porque el caso es impopular, pero Thorolf le ofrece tierras, con lo cual consigue el apoyo de Snorri. Las tierras se transfieren de acuerdo al siguiente régimen: Thorolf conservará el usufructo y a su muerte las tierras pasarán en plena propiedad a Snorri ${ }^{77}$. Entre Snorri y Arnkel existe rivalidad; Snorri aprovecha la oportunidad de ver a Arnkel desheredado. El interés de Thorolf, como subraya Miller, no es material, pues el valor de la tierra excede la compensación que obtendrá por los esclavos; ganando el caso en la asamblea, que es lo que espera lograr mediante las habilidades de Snorri, Thorolf acrecienta su reputación y reconstruye sus alianzas a partir del vínculo con un jefe prestigioso. La cesión de tierras le ha servido para desheredar al hijo, con quien se encuentra enemistado, para intervenir en la disputa entre dos jefes que compiten por ganar adeptos y para consolidar su propio status mediante el éxito de su causa en la asamblea.

El ejemplo podría iluminar algunos aspectos de la relación de benefactoría. En el caso de adulterio referido arriba, la cesión de tierras al presbítero que logra la reconciliación entre las dos familias (un aspecto independiente de la multa que percibe el conde) no resulta desproporcionada si se tiene en cuenta lo que está en juego: el futuro de la mujer que cede las tierras, que podría haber sido rechazada por su marido y perdido toda chance de volver a casarse, lo que hubiera ocasionado un grave problema a su familia, representada por el hermano. En este contexto, y ante semejantes perspectivas, el vínculo de los hermanos con un personaje destacado como el presbítero local tiene probablemente para ellos más interés que la tierra, ya que supone un reposicionamiento en la comunidad y evita un conflicto interfamiliar. Al igual que en el ejemplo anterior, la cesión de una parte de la heredad familiar-que además es retribuida con ganado y alimentos- construye una relación social que no implica explotación económica (no hay mención a tributos) sino una forma de alianza política entre hombres libres, aun cuando la operación contribuye a la formación de patrimonio para una de las partes. Este último fenómeno, que en términos generales acompaña la expansión de relaciones de explotación feudales, podría pensarse entonces como derivación de prácticas sociales de tipo arcaico (la donación de tierras para retribuir servicios de mediación) y de una estructura de propiedad que favorece

${ }^{76}$ Ibidem, pp. 126-132. El episodio en Eyrbyggja saga, ed. Paul Schach and Lee M. Hollander, Nebraska, 1959, 31.

77 Sobre las modalidades de transferencia de tierras en Islandia vid. Miller, "Avoiding Legal Judgement”, p. 126 n. 123. 
la transferencia de tierras (la explotación parcelaria individual), lo cual permitiría en principio postular la existencia de una dinámica propia de sociedades campesinas conducente, en el largo plazo, a su desintegración.

Esta evolución se observa en algunos casos donde los pactos de benefactoría surgidos por necesidad de mediación implican un mayor desbalance y la pérdida de autonomía económica para los beneficiados. Se trata en estos ejemplos de delitos que convocan a los benefactores a una de las funciones características de los jefes políticos en sociedades campesinas: prestar ayuda en los casos judiciales en los que sus hombres se ven envueltos. (Esta circunstancia podría derivarse de la vigencia relativa de una concepción primitiva del honor, que explica la frecuencia de homicidios entre campesinos y la consecuente necesidad de apoyo en los tribunales.)

La documentación del monasterio de Celanova ofrece algunos ejemplos en los que la retribución por servicios de mediación implica para los beneficiados la pérdida de su autonomía. Se trata de pactos concertados tras la comisión de un delito. En el año 1022 Gontoi y su esposa ceden a Vimara Kagitiz, mediante la fórmula de la incomuniación, la mitad de sus bienes a cambio de su ayuda en relación a las acciones de uno de los hijos del matrimonio, que ha cometido adulterio con una sobrina que vivía con ellos. Gontoi y su esposa quieren evitar las consecuencias de un juicio ${ }^{78}$, y en caso de que se llegara a esa instancia, contar con el apoyo de un hombre de Celanova en los tribunales; esta funcionalidad del benefactor se destaca en el documento: "abeamus de vobis defensionem et moderationem et in verbo et in facto et in concilio et in benefactoria" ${ }^{\prime}$. La capacidad de convencer y persuadir con la palabra, que se pone a prueba en la asamblea, distingue a los jefes en sociedades campesinas y es uno de los fundamentos de su autoridad. Este atributo se asocia a la figura del benefactor en los casos citados y pudo constituir en los inicios una de las determinaciones de la elección de jefe por parte de los beneficiados. En el caso del presbítero Evenando que interviene en una disputa interfamiliar la capacidad persuasiva es la clave de su actuación ("et favolastis pro me"); en la incomuniación entre Gontoi y Vimara, en cambio, la alusión a las facultades oratorias y al desempeño en la asamblea ("defensionem in verbo... et in concilio") parece responder a un formulismo que acompaña la mención al benefactor antes que a las cualidades específicas de éste o a su funcionalidad; de hecho la clave de la actuación de Vimara no es la persuasión sino su vinculación con el monasterio de Celanova. Esta procedencia explica las condiciones de la cesión de propiedad: los beneficiados conservan la posesión de las tierras, y el benefactor obtiene el derecho a apropiarse del fruto ${ }^{80}$.

78 "Super hoc pretextum et definicione ut si quod absit in quacumque tempore aliquis homo vos proinde inquietare aut calumniare presumere voluerit tam de parte regia aut comitum vel pontivilagium aut decius propago vel posteritati fuerit, licitum habeatis vos Vimara Kagitiz nos de illorum manus et de eius iudicio eicere, ut non sit nobis inde nullum impedimentum aut damnum vel etiam aliqua disturbatura tam nobis quam etiam, et filiis nostris nisi sani et salvi remaneamus cum pace", ANDRADE, José M., O Tombo de Celanova, II, Santiago de Compostela, 1995 (en adelante Tumbo de Celanova), doc. 547 (1022).

79 Tumbo de Celanova, doc. 547 (1022).

80 "Et demus vobis per annis singulis ad area et at lagare medietate tam de pane et bibere quam etiam et de omnes fruges quod Dominus in ipsa villa dedit, medium vobis demus et medium remaneat 
En otro caso, del año 1012, Daildo es acusado de rapto por los sayones del rey, el conde Rodrigo Ordóñez y el padre de la víctima ${ }^{81}$. Aloiti, ex abad de Celanova ahora transferido a otro monasterio, acude al lugar de los hechos y paga la multa por rapto; en agradecimiento Daildo le ofrece dos villas, una de las cuales al parecer no le pertenece ${ }^{82}$; el engaño se descubre y Daildo es acusado de calumnia y conminado a duplicar la cesión de tierras a favor de Aloiti (debe ceder dos tierras en reemplazo de la falsa, además de la que ya había dado). Tras la intervención de ciertos homines idoneos qui fabularunt (los que en rigor cumplen la función de mediación), y en una escena de gran despliegue actoral, Aloiti se compadece de su beneficiado y le otorga el perdón, por lo que Daildo acaba perdiendo dos propiedades en lugar de tres ${ }^{83}$. Las palabras del que preside la asamblea, dirigidas al benefactor Aloiti, atestiguan que el vínculo de benefactoría se concibe aquí en términos de subordinación y disciplinamiento: "Venistis ad ipsum monasterium ad corregendum, ad salvandum, ad moderandum, ad benefaciendum ad oves Dei que iam disperse erant" ${ }^{\text {"84. Daildo seguirá }}$ cultivando las dos tierras, por las que dará ahora un tercio del fruto como renta al monasterio de Celanova ${ }^{85}$.

A diferencia de nuestro primer caso (la cesión de tierras al presbítero local que consigue la reconciliación entre dos familias), en los dos últimos los cedentes mantienen el usufructo de las tierras que donan y quedan comprometidos al pago de rentas, por lo cual la relación de benefactoría ya no expresa una alianza entre hombres libres sino la entrada en dependencia para una de las partes. Asimismo, mientras que en el primer caso el benefactor mediaba en un conflicto interfamiliar, en los dos últimos la mediación tiene en teoría el objeto de mitigar los efectos del ejercicio de la justicia sobre el acusado, que evidentemente trascienden la satisfacción de la multa por el delito. Este aspecto de la mediación se destaca en los dos documentos ("et eiecistis nos de illorum manuum et de sua ligamine") ${ }^{86}$, de lo cual se deduce que la entrega de tierras a los benefactores, que tiene antecedentes en prácticas tipológicamente arcaicas, se ve favorecida y aun inducida por un contexto donde la justicia constituye una

pro nobis", Tumbo de Celanova, doc. 547 (1022).

81 "Damus vobis ambas ipsas villas pro intentio quod nobiscum abuerunt saiones de Rex domnus Adefonsus et de comes Roderico Hordoniz que omnem terram Limie iuri suo obtinebat, et Gurderigo Dodilaz cum eos pro peccato impendiente quod nobis evenit et rausavimus filia de ipse Gurderigo et postea calumnaverunt nos pro tale actio, et devenerunt nobiscum proinde ad veritate in concilio monasterii Cellenove", Tumbo de Celanova, doc. 572 (1012).

82 "Et peccato nobis impendiente presumimus ipsa villa Domenezi et tulivimos ea de iuri monasterio et plegavimus iuri nostro extra veritate", Ibidem.

83 "Et dum talia vidimus et aures audivimus et non habuimus unde omnia ipsa villa componere per lege, fabulauimus ad homines idoneos qui fabularunt vobis ad misericordia et pro vestra mercede vidistis et intellexistis lacrimis et suspiriis vestris et posuistis aurem ad audiendum, et cor ad intelligendum et dimistis nobis ipsam calumniam de ipsam villam quod abebamus ad duplare", Ibidem.

${ }^{84}$ Ibidem.

85 "Ut demus vobis pannis singulis ad area et at lagare tercia integra, tam de pane quam de bibere", Ibidem.

86 Ibidem. 
fuente de ingresos y un instrumento de subordinación ${ }^{87}$. Estos casos ilustran la transmutación de la práctica campesina en un contexto feudalizado: la entrega de tierras para recompensar los servicios de mediación de juristas destacados, una herramienta de negociación del status en sociedades campesinas, se convierte en el nuevo marco en un mecanismo de absorción de propiedades y de expansión de relaciones de explotación feudales, conservando en distintos grados la forma de la práctica arcaica, según la cual el mediador se presenta como una figura capacitada para conducir exitosamente la causa en la asamblea o para representar a una de las partes.

En otros casos el desarrollo de relaciones de explotación en el área se manifiesta en la disputa entre fracciones de la clase dominante cuyo objeto son aquellos que aún no han sido incorporados al sistema de renta: el benefactor intenta la defensa de sus clientes libres frente al avance señorializador de otros poderes.

La documentación de Celanova proporciona un ejemplo de esta situación, donde también puede verse con mayor riqueza de detalles la actuación del benefactor dentro y fuera de la asamblea en ocasión de un delito cometido por uno de sus clientes. Sánchez Albornoz se ha referido a este documento, en su criterio ilustrativo de las obligaciones del patrono en una relación de benefactoría. Se trata de un caso de homicidio que involucra a un cliente del conde Sancho y al monasterio de Celanova ${ }^{88}$. Tedón, maullatus del conde Sancho, ha matado con su lanza a un hombre del abad de Celanova, por lo que es encadenado y conducido a la cárcel. Su mujer ofrece al abad una tierra como fianza y logra que quiten las cadenas a Tedón hasta que se resuelva su situación. Una vez libre Tedón se moviliza en busca de apoyos: acude a su benefactor, el conde Sancho, a quien le narra su propia versión de los hechos, según la cual lo han apresado sin motivos. El conde, ante el relato de Tedón, se muestra enfurecido y envía un hombre suyo a pedir explicaciones al abad ${ }^{89}$; el enviado no cree en la versión del monasterio y continúa defendiendo a Tedón, por lo que el caso se lleva a la asamblea, donde el conde, que la preside, discute enérgicamente con los hombres de Celanova ("baraliaverunt de ista actio non modica sed multa causa"), aunque sus esfuerzos resultan infructuosos. Como último recurso, el conde propone nombrar testigos que juren que Tedón obró en defensa propia ("et iurassent... qui illo homine tenuerat ad capillos quando eum plagaverunt lancea") para que éste pueda

${ }^{87}$ Sobre la formación de patrimonio mediante el ejercicio de la justicia vid. SAnCHEZ Albornoz, Claudio, El régimen de la tierra en el eino asturleonés hace mil años Buenos Aires, 1978, cap. 2, y AsTARITA, Carlos, "Tesis sobre un origen gentilicio patrimonial del feudalismo en el noroeste de España. Revisión crítica", Anales de Historia Antigua, Medieval y Moderna, 39 (2007) pp. 116 y ss. En relación a algunos de los ejemplos citados se ha propuesto que la incomuniación es una forma de profiliación orientada a la absorción de propiedades cuando éstas son poseídas colectivamente, IsLA FrEZ, Amancio, "Las relaciones de dependencia en la Galicia altomedieval: el ejemplo de la incomuniación", Hispania, XLIV, 156 (1984). Esta última circunstancia no se constata en los casos analizados.

${ }^{88}$ SÁnchez Albornoz, "Las behetrías", pp. 89-90. El documento completo en Tumbo de Celanova, doc. 474 (1056), pp. 656-658.

89 "Ille comite talia audiente casa non fuit illi placibile, sed exarsit nimis in forore et ira pro suo mallato, que absque veritate iudicaverant et tanta mala sustinuerat. Tunc suscitavit homine bono nomine Sandino... et direxit ad ille abba pro qua causa talia egisset", Tumbo de Celanova, doc. 474 (1056). 
ser exonerado ${ }^{90}$; cinco personas dan su testimonio, después de lo cual se procede, mediante un intermediario, a la prueba del agua caliente, que resulta favorable al monasterio de Celanova. Tedón y su esposa se retiran angustiados de la asamblea, tal vez porque esperaban otro desenlace teniendo como aliado al conde; para pagar el homicidio deben ceder una tierra ${ }^{91}$.

El ejemplo ilustra el contexto en el que actúan los benefactores, donde el ejercicio de la justicia se presenta como un mecanismo de acumulación patrimonial para la parte acusadora, que en este caso no se identifica con el interés sectorial del benefactor. Al contrario, éste no desea que su cliente, un propietario libre, quede bajo la sujeción de un contendiente feudal, y por este motivo lo defiende incansablemente en la asamblea con argumentos tan ingeniosos como inverosímiles (recordemos que Tedón ha matado a un hombre), recreando la forma de actuación política de los jefes primitivos. Aun cuando la mediación del conde no resuelve el problema a Tedón, que pierde una propiedad a manos del monasterio de Celanova, el vínculo clientelar conserva la forma característica de la práctica campesina. El contexto, sin embargo, altera la sustancia de la relación, por cuanto desplaza la actuación del benefactor del campo de la negociación del status al de la competencia entre fracciones de la clase feudal y pone en juego la autonomía económica del beneficiado.

No hay en la documentación de Sahagún evidencia equivalente, donde pueda observarse la actuación de los benefactores en la asamblea. La administración de justicia en el lugar, sin embargo, aparece como determinación secundaria de la elección de jefe: Citi Pérez, por ejemplo, podrá elegir a "quibus voluerit de heredes mei qui in ipsam villam iussionem habuerint" ${ }^{\prime \prime 2}$. Esta condición, si bien aparece subordinada al derecho hereditario, podría indicar que la intervención del benefactor en los litigios judiciales de sus clientes sigue siendo un elemento característico de la relación, aunque esta actuación, según se ha visto en otras áreas, se orienta ahora hacia la absorción de propiedades o hacia la defensa de la base clientelar cuando el que absorbe propiedades es un poder rival.

Correlativamente a la jerarquía de la actuación judicial de los benefactores, la obligación de acompañar al señor a la asamblea (uno de los contenidos de la relación goðar-boendr) pudo ser parte del servicio que debían brindar los beneficiados. En el fuero de León ésta es una obligación de los milites que habitaran solares ajenos, quienes deberán acompañar al dueño del solar a la asamblea a la que este último concurre $^{93}$. La asistencia de los beneficiados a la asamblea se comprueba en algunos

90 "Ille vero comite ordinavit eis ut dedissent de ipsa com $\backslash 1$ latione qui ibidem fuerant ubi ipso omicidio fuit. Facto $\mathrm{V}$ testimonias ille monacho per se et alias quator de ipsos homines meliores, et iurassent super ipso Tetone et super sua mulier qui illo homine tenuerat ad capillos quando eum plagaverunt lancea, et eiecissent de pena et quod domnus iudicasset inde hoc et fecissent", Ibidem.

91 "Illos vero non habuerunt unde ista omnia adimplere, sed molestia detemti tulerunt se de concilio. At ubi iudex vidit talia prosequentes et ad concilio nullatenus venientes mandavit suo saione ut adsignasset ad ille abba et ad suos fratres hereditate de Mortaria sicut et fecit. Et teneant ea usque reddat ipse Tetone et sua mulier ipso omicidio sicut veritas docet", Ibidem. La cesión de la tierra al monasterio de Celanova en doc. 475.

92 Sahagún, doc. 549 (1051).

93 "Si vero miles in Legione in solo alterius casam habuerit, bis in anno eat cum domino soli ad iunctam... et habeat dominum qualemcumque voluerit", Fuero de León, XXVI, MuÑoz y Romero, 
casos: el mencionado Citi Pérez aparece tiempo más tarde en la documentación de Sahagún como confirmante ${ }^{94}$; Velite Cítiz, que en 1086 recibe un solar de Martín Flaínez con fuero de benefactoría, figura como confirmante al año siguiente ${ }^{95}$; Vela Velázquez, el collazo a quien Pelayo Vermúdez otorga un solar en 1092 para que sirva a quien quiera, aparece actuando como confirmante tres años después de la donación ${ }^{96}$; a Pedro Iústiz, que en 1085 obtiene una corte con la facultad de elegir señor libremente, lo encontramos como confirmante poco tiempo después ${ }^{97}$; éste también es el caso de Juan Mániz, que aparece primero como beneficiado y unos años más tarde como confirmante ${ }^{98}$; en 1097 Pedro Cítiz y sus hermanos litigan con el abad de Sahagún por varias tierras, a raíz de lo cual acuden "ad iunctam ad comite domno Sanxo", probablemente en busca de apoyo frente a las aspiraciones del abad; finalmente éste acuerda con los hermanos que unas tierras quedarán para Sahagún y con las otras podrán ir al señor que quieran (ubi uolunt) siguiente ${ }^{100}$. Estos testimonios indican también que los beneficiados, a quienes hemos identificado mayormente como campesinos, aún no han sido totalmente desplazados de los tribunales públicos.

\section{LA FACULTAD DE ELECCIÓN DE JEFE}

La capacidad de elegir señor se presenta en los documentos como un atributo de los hombres libres, no sujetos a un vínculo de dependencia que condicione su movilidad. Así lo explicita un diploma donde se dona un solar con sus adyacencias en plena propiedad, "sicut alios homines bonos habent suos solares", estableciéndose luego que "faciatis alium dominum quemcumque volueritis" ${ }^{101}$. La facultad de elección de señor acompaña las cartas de ingenuidad, lo cual confirma que la benefactoría es una relación asociada a la libertad: "sit ingenimo tu et filiis tuis et serbias tu et filiis tuis a quales domnos quesieris" 102 .

El fuero de León de 1020 define al hombre de benefactoría por la libertad de movimientos: el que participa de una relación de benefactoría no pierde sus bienes si se traslada o cambia de benefactor ${ }^{103}$. Esta capacidad lo distingue del junior, quien en caso de mudarse perderá la mitad de las heredades ganadas a manos del señor ${ }^{104}$.

\footnotetext{
Colección de Fueros municipales, p. 67.

${ }^{94}$ Sahagún, doc. 635 (1063).

${ }_{95}$ Sahagún, doc. 826 (1086) y 836 (1087).

${ }_{96}$ Sahagún, doc. 887 (1092) y 985 (1095).

${ }_{97}$ Sahagún, doc. 818 (1085) y 851 (1089).

98 Sahagún, doc. 1086 (1102) y 1141 (1106).

99 Sahagún, doc. 1015 (1097).

${ }_{100}$ Sahagún, doc. 1031 (1098).

101 Sahagún, doc. 1252 (1133).

102 Archivo Catedral de León, doc. 894 (1031).

103 "Praecipimus adhuc, ut homo qui est de benefactoria, cum omnibus bonis et haereditatibus suis eat liber quocumque voluerit”, Fuero de León, tit. XIII, MuÑoz y Romero, Colección de Fueros municipales, p. 64.

104 "Praecipimus etiam ut nullus nobilis sive aliquis de benefactoria emat solare aut ortum alicuius junioris, nisi solummodo mediam hereditatem de foris; et in ipsam medietatem quam emerit, non fa-
} 
Jurídicamente los hombres de benefactoría serían aquellos que han concretado o formalizado un pacto con alguna persona de superior jerarquía sin perder su libertad de movimientos, propia de su condición de libres, y manteniendo, en distintos grados, la facultad de cambiar de patrono.

Aun cuando las relaciones de benefactoría se desarrollan en territorio feudalizado, donde la autoridad tiene existencia independiente y una base regular, aunque acotada, de extracción de excedentes, se trata de alianzas pactadas voluntariamente: los homines de benefactoria eligen a quién vincularse, lo cual pone de manifiesto el carácter relativamente inestable del poder del benefactor, cuya posición en principio depende de sus cualidades como mediador, de su prestigio en la comunidad, de su capacidad de negociación o de su generosidad en los casos en que los beneficiados son dotados con tierras o con caballos.

La inestabilidad es el rasgo característico de las jefaturas en sociedades campesinas. En Islandia todo hombre libre al frente de una unidad doméstica debe estar adscripto a un goði, al cual puede elegir y abandonar (el cambio de jefe puede hacerse durante determinados días cada primavera). La autoridad del goði, con independencia de la heredabilidad del cargo, depende de su ascendiente sobre los hombres adscriptos a su jefatura, quienes pueden retirar su lealtad y vincularse a otro jefe del distrito $^{105}$. Hemos visto un ejemplo en la saga de Eyrbyggja, cuando Thorolf traslada su apoyo a Snorri el goði. La saga de Njal proporciona un caso paradigmático: Mord, que ha heredado y ejerce el cargo de goði, se queda sin seguidores porque éstos se han pasado a la jefatura de Hoskuld (el apadrinado de Njal); el lugar donde solía celebrarse la asamblea local, normalmente provisto de instalaciones precarias, se encuentra abandonado, pues al modificar su lealtad los hombres se trasladan al punto donde convoca habitualmente a asamblea el jefe que han elegido ${ }^{106}$. La existencia de la comunidad se expresa en la reunión de los propietarios individuales; correlativamente, la autoridad se expresa en el apoyo efectivo de estos últimos: al perder sus seguidores Mord pierde los poderes de su jefatura, sobre la que tiene derechos hereditarios.

Los diplomas de Sahagún y otros documentos donde se regulan relaciones de benefactoría se refieren a la capacidad de elegir señor por parte de los que suscriben el pacto o reciben el fuero o aceptan una dotación de tierras. En la mayoría de los diplomas del siglo XI la donación no indica restricción alguna respecto a las vinculaciones que pudieran establecer los beneficiados: la expresión característica es "vadas cum eo ubi volueris, tu et filius tuus et omnis progenis tua"107, o bien "ad unos aut alios

ciat populationem husque in tertiam villam. Junior vero qui transierit de una mandatione in aliam, et emerit haereditatem alterius junioris, si habitaverit in eam, possideat eam integram; et si noluerit in ea habitare, mutet se in villam ingenuam husque in tertiam mandationem, et habeat mediatatem praefatae haereditatis excepto solare et horto", Fuero de León, tit. IX, MuÑoz y Romero, Colección de Fueros municipales, p. 63.

${ }^{105}$ Miller, "Avoiding Legal Judgement"; Wickham, Chris, "Problemas de comparación de sociedades rurales en la temprana Edad Media", trad. esp., Anales de Historia Antigua y Medieval, vol. 29 (1996), pp. 62-63.

106 Njal's saga, 107.

107 Sahagún, doc. 1086 (1102). 
domnos, qui tibi bene fecerit" ${ }^{108}$. La inclusión de este tipo de fórmulas probablemente responde a la motivación de reafirmar la condición de hombre libre (o la promoción al estatus de libre) del que recibe las tierras, uno de cuyos atributos es la posibilidad de modificar lealtades. En los casos en que los beneficiados reciben alodios o prestimonios militares esta capacidad tal vez se hacía efectiva después de la muerte del benefactor, aunque el beneficiado podía en teoría abandonar al jefe elegido, según se indica en 23 de los diplomas analizados ${ }^{109}$. Si bien esta variante no debe descartarse, el hecho de que otros diplomas introduzcan cláusulas restrictivas respecto a la durabilidad del vínculo podría sugerir que empiezan a asentarse por escrito elementos nuevos de la práctica real, la cual tal vez no contemplaba la posibilidad del cambio de benefactor.

La facultad de elección de jefe implica que el beneficiado, antes o más probablemente después de la muerte del benefactor, en teoría es libre de prestar su apoyo a miembros diversos de la nobleza. Gonzalo Cipriániz, que recibe una tierra con fuero de prestamero, podrá elegir "a quale dono quesieri: a rege, a comite, ad episcopo, ad abas, a Kastella, a Gallezia" "110, es decir, buscará jefe en el conjunto de la aristocracia y sin límites geográficos. En otros diplomas el espectro aristocrático se identifica con los dos principales linajes: los beneficiados podrán elegir "inter casata de Vanamirel aut inter casata de Alfonso Didaz" ${ }^{\prime 11}$. Aunque esta limitación reduce el conjunto de potenciales benefactores, formalmente se mantiene el criterio de que son elegibles aquellos que ostentan determinadas cualidades -con independencia de que éstas se adscriban a las principales familias nobles- al igual que sucede en sociedades campesinas (en Islandia, por ejemplo, los hombres eligen jefe entre un número limitado de goðar), con lo cual aún se reconoce a los beneficiados cierto protagonismo político. Este criterio se desplaza cuando los benefactores, a la hora de referirse a la facultad de elección de señor, toman partido por uno de los dos principales linajes, con lo cual el espectro de posibles alianzas políticas se limita sensiblemente ${ }^{112}$. Por último la facultad de elección de patrono quedará restringida al linaje del benefactor ("inter meos heredes qui tibi melius fecerit", etc) liar se impone como principal determinación de la condición de jefe. En algún caso los benefactores incluso restringen las vinculaciones de los beneficiados a personas puntuales de su grupo familiar: Urraca, miembro del linaje de los Alfonso, establece que después de su muerte el sujeto a quien ha beneficiado con una tierra, Rexendo, podrá elegir entre los hijos y nietos de dos de sus hermanos, las hijas de una hermana

108 Sahagún, doc. 825 (1086).

109 Sahagún, doc. 566 (1054), 624 (1063), 634 (1063), 676 (1068), 702 (1071), 713 (1072), 719 (1973), 737 (1074), 778 (1080), 788 (1080), 795 (1081), 818 (1085), 824 (1086), 825 (1086), 887 (1092), 1015 (1097), 1086 (1102), 1173 (1085), 1189 (1113), 1198 (1117), 1252 (1133); Archivo Catedral de León, doc. 894 (1031), 1233 (1084).

110 Sahagún, doc. 804 (1083).

111 Sahagún, doc. 752 (1077).

112 "Vadatis cum illo inter filios et neptos de Vani Mirelliz, Sahagún, doc. 1077 (1101); inter casata de Vani Mirel ad quale tibi melius fecerit, doc. 811 (1084); et vadeas cum eo medio die et media ora inter Vani Mirel qui tiui melior fecerit tu et filiis tuis et neptis tuis vel viisneptis", Archivo Catedral de León, doc. 1192 (1073).

113 Sahagún, doc. 1096 (1103), 1125 (1105), 826 (1086), 893 (1092), 959 (1095), 549 (1051). 
y los hombres del monasterio de Sahagún ${ }^{114}$. De acuerdo a los datos que se conocen sobre esta familia Rexendo podrá elegir señor entre unas veinte personas. (Este tipo de caso podría ilustrar el mecanismo de formación del plantel de diviseros que aparece en las behetrías de los siglos XIII y XIV, que las fuentes señalan en número similar, y que en principio se presentan como los candidatos al señorío superior en virtud de su pertenencia a un linaje determinado.)

Esta evolución, tendiente a limitar las alianzas del beneficiado, se manifiesta también en los diplomas donde los benefactores aseguran el servicio hasta su muerte, después de la cual los beneficiados pueden elegir jefe libremente ${ }^{115} \mathrm{o}$ dentro del linaje del benefactor ${ }^{116}$, lo que en términos de Weber expresaría un principio de objetivación del carisma, y en términos del modo campesino una incidencia residual del campesinado en las redes políticas aristocráticas, lo cual implica su negación como forma social.

La imposición a los beneficiados de servir a un jefe de por vida y permanecer bajo la órbita de una misma familia expresa la resignificación de la práctica campesina, que tiende a colocarse al servicio de la lógica feudal manteniendo en distintos grados su forma originaria, lo que explica la conservación del formulismo de la elección de señor y los sucesivos recortes que esta facultad sufre en la práctica, los cuales se incorporan paulatinamente en las escrituras.

En ocasiones esta tendencia se ve favorecida por algunos contenidos de la práctica campesina, como en el caso del vínculo de crianza, que según se ha visto compromete a los padrinos de manera permanente con la familia del dador, y a los apadrinados con la familia sustituta. Proporciona un ejemplo el caso ya analizado de Diego Pátriz y su padrino Tello, en el que el pacto de benefactoría incluye una cláusula aclaratoria respecto a la durabilidad del vínculo: "tantum in diebus nostris non permitto te servire cum illo alio domno" ${ }^{117}$. El padrinazgo implica, a su vez, un compromiso de lealtad que se pone a prueba en el conflicto interfamiliar, de lo cual resulta la implicación de los homines de benefactoria en las disputas de sus señores; este tipo de vínculo, tanto en su forma asimétrica como en la paralela, pudo constituir un mecanismo de reclutamiento de seguidores permanentes que contradice la capacidad formal de libre elección de jefe propia de la benefactoría, y que facilita la tendencia de los benefactores a limitar el círculo de los elegibles a los miembros de su familia. Se podría entonces conjeturar que las prácticas sociales originarias del modo campesino contienen elementos contradictorios que promueven una evolución hacia vínculos más estables, lo cual en un contexto feudalizado contribuye a la readaptación de la práctica campesina a los requisitos de la dominación aristocrática.

La tendencia a restringir la elección de jefe al propio linaje es incipiente en el siglo XI, y dominante en el XII, cuando las relaciones de benefactoría ya no implican a individuos sino a comunidades enteras. Tal el caso del conde Gonzalo Núñez,

114 "Et post mortem meam uadas inter filios et neptos de fratribus meis domno Monio et domno Gutier aut inter filias de domna Adosinda, soror mea, nominatas Goto et Monia, aut a domnos de Sancto Facundo, uel qui tibi melior fecerit”, Sahagún, doc. 620 (1062).

115 Sahagún, doc. 606 (1059), 721 (1073), 953 (1095).

116 Sahagún, doc. 620 (1062), 952 (1095), 728 (1074).

117 Sahagún, doc. 606 (1059). 
que en 1089 otorga fuero a los pobladores de Andaluz, estableciendo que hayan behetría entre "mis fijos e mis nietos e en todo mi linaie" "18. Una cláusula del fuero deja ver el mecanismo por el cual la elección de señor pasa a convertirse en una práctica colectiva: "et ser todos dun sennor et do fueren la mayor partida que vayan los otros" 119 . El interés del poder superior por disciplinar a los habitantes respecto a sus vinculaciones políticas se refleja en la normativa del xII: el fuero otorgado a los habitantes de Fresnillo en 1104 por el conde García Ordóñez prohíbe la coexistencia de alianzas diferenciadas, obligando a elegir entre alguno de sus descendientes ${ }^{120}$. La misma preocupación se observa en el fuero dado a los pobladores de Escalona en 1130, orientado a uniformar los vínculos de los vecinos ("non eritis divisi") y limitarlos a la familia del dominus del lugar' ${ }^{121}$. También el fuero de Belbimbre de 1187 intenta reprimir la concertación de alianzas múltiples en una misma aldea, estableciendo que los habitantes no se sometan a más de un señor ${ }^{122}$. El mismo fuero permite a los milites vincularse al señor que quieran ${ }^{123}$, lo cual confirma que la capacidad de elección de señor se asocia en términos generales a la libertad, y que en el siglo XII este concepto empieza a identificarse exclusivamente con la condición de privilegio.

La facultad de elección de jefe perderá definitivamente su contenido político original cuando la actuación del benefactor, o el derecho a ser elegido como tal, se materialicen en la exigencia de rentas. Veamos entonces cómo se presenta este problema en la documentación.

\section{LA PRÁCTICA DE LA HOSPITALIDAD Y LA EXIGENCIA DE TRIBUTOS}

Se han examinado algo más de cuarenta diplomas de la colección de Sahagún, de los cuales sólo tres aluden al pago de rentas.

Uno es el caso ya analizado de Velite Álvarez, criado de la familia de Pedro Muñoz, a quien en 1064 se conceden dos solares y tres tierras para que tome posesión

118 Citado por SÁnchez Albornoz, Claudio, "Muchas páginas más sobre las behetrías”, en Viejos y nuevos estudios sobre las instituciones medievales españolas, I, Madrid, 1976, p. 209. El fuero (una traducción al romance del original latino) está disponible en: http://es.wikisource.org/wiki/Fuero_de_ la_Comunidad_de_Villa_y_Tierra_de_Andaluz_de_1098

119 Fuero de Andaluz, Ibidem.

120 "Et non intretis in temptacione nec particione, sed abeatis benefectria cum vestras causas ad filiis nostris vel neptis seu ad qualem vobis placuerit aut meliore fecerit, ut ipsi serviatis", Fuero de Fresnillo, tit. 13, Hinojosa, Documentos, XXIX (1104), p. 47.

121 "Vos vero in diebus nostris non eritis divisi et post nostram mortem et filiis nostris cui volueritis et melior vobis fecerit, ipse servite cum omnia vestra bona", MuÑoz y ROMERO, Colección de fueros municipales, p. 485.

122 "Omnes habitatores... unius tantum domini prestamerii adhereatis, et nulli liceat uos per partes diuidere, aud plurium dominorum dominatui subicere", Fuero de Belbimbre y sus cuatro aldeas (1187), tit. 9, Martínez Díez, Gonzalo, Fueros locales en el territorio de la provincia de Burgos, Burgos, 1982, doc. XXIX, p. 179.

123 "Preterea omnibus uobis qui milites fueritis in Beneuiuere et in predictis quatuor barriis indulgeo et concedo quod nullam facenderam pectetis, et habeatis dominos quales habere uolueritis et domos uestras liberas possideatis", Fuero de Belbimbre y sus cuatro aldeas (1187), tit. 5, Ibidem. 
de ellas y las trabaje ${ }^{124}$. En base a este ejemplo Martínez Sopena ha propuesto que la benefactoría es una forma de reclutamiento de mano de obra para la reserva. El caso, además de ser excepcional, tiene otros matices: Velite retribuye la donación con un caballo, un galgo y un podenco, lo cual sugiere que aun siendo un sirviente tiene un estatuto especial, que podría explicarse por el hecho de que Velite ha criado al conde Pedro Muñoz, lo cual lo distingue de otros sirvientes. Cuatro años después de esta cesión, que realiza la condesa Mumadonna, su hijo Pedro Muñoz pide tierras a Alfonso VI para dotar a Velite ${ }^{125}$. El hecho de que el conde solicite tierras a terceros para realizar la dotación descarta el cultivo de la reserva como motivación del pacto. Velite, como sirviente de la familia de Pedro Muñoz, realiza las tareas que se le ordenan, lo cual incluye la puesta en cultivo de tierras familiares, que aparece en el diploma de 1064; su condición de sirviente, sin embargo, es indiferente al vínculo con el conde, fundado en una relación de crianza. Siguiendo ejemplos análogos de las sagas islandesas, como el de Skarp-Hedin y su padrino Thord, que también es un sirviente, hemos comprendido este tipo de vínculo como una forma de intercambio de dones. Esta perspectiva explica las gestiones que realiza el conde en 1068 para dotar con tierras a la persona que lo crió, a quien quiere promocionar y con quien tal vez se encuentra especialmente unido, y explica también el hecho de que en esta segunda donación no exista mención alguna a la satisfacción de rentas. La benefactoría, por último, es la fórmula para expresar la promoción, ya que Velite, que dispone limitadamente de la heredad que recibe, tendrá movilidad plena sobre las tierras que obtuviera por compra o por otros medios ${ }^{126}$, una facultad que lo segrega de la condición servil según el fuero de León ${ }^{127}$.

El segundo caso es un diploma en el que se otorgan fueros diferenciados: la condesa Ildonza González dona a dos de sus collazos, para que pueblen su heredad, un solar con un fuero favorable, que los exime de un conjunto de rentas aunque los obliga con 12 días de prestaciones de trabajo; simultáneamente les otorga alio foro, referido no al solar de la donación sino a las comparationes, adpresuras, maliolos, etc., es decir las tierras que estos collazos pudieran adquirir por compra o presura, con las cuales podrán servir al señor que elijan de entre ciertas personas (los herederos de Trigueros) ${ }^{128}$. El vínculo de benefactoría no involucra el solar gravado con prestaciones de trabajo sino las tierras obtenidas por medios propios; estos collazos, promovidos a la condición de libres en tales tierras (por lo cual no las pierden si se trasladan, de acuerdo al fuero de León), estarían participando de dos vínculos diferenciados: uno con la condesa que les exige prestaciones de trabajo en base al solar

124 "Ed damus cum eos foro que prendas in nostra diuisa et ares quantum potueris", Sahagún, doc. 638 (1064).

125 Sahagún, doc. 675 (1068) y 676 (1068), vid. supra.

126 "Ut habeat ipsa corte cum omni hereditate que ad ipso solare pertinet; et quantum super hoc ganauerit uel plantauerit uel hedificauerit uel etiam comparauerit, liberam habeat possidendi potestatem", Sahagún, doc. 675 (1068).

127 Fuero de León (1020), tit. IX, MuÑoz y Romero, Colección de Fueros municipales, p. 63, vid. supra. Sobre la movilidad del junior en el fuero de León de 1017 y 1020 y sobre este título en particular vid. SÁnchez Albornoz, "Muchas páginas más sobre las behetrías”, pp. 221-249.

128 Sahagún, doc. 893 (1092). 
cedido, quedando los collazos bajo la autoridad política del rey, y otro con el benefactor que eventualmente eligieran ("vadatis cum vestras comparationes... ad illos ereteros de Tridigarios et nos ad illo rex"). De manera semejante al caso anterior, la apelación a la fórmula de la benefactoría podría reflejar la intención de promover a los collazos a un mejor estatuto personal, que acompaña la estrategia de asentar dependientes (una práctica vinculada a la necesidad de afirmar la propiedad frente a otros señores) ${ }^{129}$, que en vista de las franquicias otorgadas parece ser la motivación principal del pacto ${ }^{130}$.

En el tercer caso, si bien no se mencionan tributos, el beneficiado cultiva tierras ajenas: Adosinda Gutiérrez cede a Monio Cítiz un conjunto de bienes que incluyen la mitad de una viña que Monio venía cultivando ("illo medio de illas uineas que tenes de me") ${ }^{131}$. Se deduce que el servicio que Adosinda espera de Monio no es la entrega de excedente agrario, el cual Adosinda probablemente obtenía en la viña en cuestión y tal vez resigna en la cesión, en la cual Monio obtiene derechos sobre un bien que anteriormente usufructuaba. Este caso podría tener cierto paralelo con el de Martino Muñiz, a quien el benefactor le cede en plena propiedad un caballo suyo que Martino venía utilizando ("et illum cauallum quem tenes de me, habeas solutum")

En estos ejemplos, si bien se manifiesta el grado de desarrollo de la relación de explotación feudal en el área (por ejemplo en la difusión de prestaciones de trabajo), el pacto de benefactoría no se presenta como un mecanismo de subordinación sino como una fórmula para promocionar a individuos en relación de dependencia, con quienes la aristocracia mantiene una vinculación ambivalente que oscila entre la exigencia de rentas y la necesidad de retribuir otro tipo de servicios. En este sentido, el predominio del modo de producción feudal es compatible con la pervivencia de usos arcaicos por parte de los miembros de la aristocracia, a quienes no debemos pensar como agentes externos a la práctica social que modifican sino como actores sociales que aún participan genuinamente de alguno de sus contenidos. Esta ambivalencia de la praxis aristocrática se expresa en la promoción a collazos y criados con funciones de crianza, la cual se formaliza mediante pactos de benefactoría.

El resto de los diplomas del XI relativos a vínculos de benefactoría no aluden al pago de rentas. Los homines de benefactoria referidos en la documentación de Sahagún, según hemos establecido, mantienen vínculos de crianza o brindan a los benefactores prestaciones militares o apoyo político. Éste parece ser el contenido del seruitium que se retribuye o que se espera de los beneficiados. Las tierras que éstos reciben por lo general tienen como único fuero el que confirma la libertad de elec-

129 Morsel, La aristocracia medieval, p. 208.

130 "Facio ad vobis karta qui populetis in mea hereditate... et damus ad vobis tale foro... que non faciatis montanera, ne fossatera, ne nucio, ne magneria, nisi que detis in anno xII dies ad nostros lavores", Sahagún, doc. 893 (1092).

131 Sahagún, doc. 636 (1064).

132 Sahagún, doc. 1173 (1085). 
ción de señor ${ }^{133} \mathrm{o}$ el que obliga a servir a determinada familia ${ }^{134}$. En los pocos casos en que se explicita otro fuero con el cual vienen dotadas las tierras transferidas, éste es ventajoso: el solar que recibe Citi Mémez en 1105 está exento de caloñas y penas por homicidio y rapto ${ }^{135}$; la heredad que obtiene Salvador Vellítiz en 1086 goza un privilegio de inmunidad ("ut non intret saio pro omicidio nec pro rauso") ${ }^{136}$. En uno de los pactos de benefactoría que registra la documentación de Cardeña el solar cedido está exento de fonsadera y servicios de vigilancia ${ }^{137}$. Al igual que en los casos anteriores, en éstos se expresa a la vez el marco feudalizado en que se inscriben los pactos y el reconocimiento del mejor estatuto de los homines de benefactoria, que aquí se manifiesta en la exención de tributos.

En algunos diplomas las tierras se entregan con "fuero de préstamo" o con "fuero de prestamero", sin indicación de una contraprestación material, de lo cual se deduce que si ésta existía era de naturaleza informal. En uno de los documentos que presenta García de Valdeavellano en su estudio sobre el prestimonio se observa que el cesionario, que prestará al cedente servicios no agrarios ("sicut vassallus domino... seruiam"), debe ofrecer a su señor una comida cuando éste atraviese el territorio objeto de la cesión ${ }^{138}$.

Teniendo en cuenta que contribuir al sostén de la corte durante sus desplazamientos en principio es una carga pública, al igual que el servicio militar y la asistencia a la asamblea, es probable que la provisión de comidas al señor en ocasión de su paso por el lugar haya constituido una contraprestación no expresa en los textos de Sahagún. Esta práctica es consistente con los servicios brindados por los beneficiados, los cuales hemos comprendido como derivación de formas de intercambio recíproco. En una de las escrituras de Sahagún - aquélla en la que se otorga una tierra dotada de inmunidad- la cesión es retribuida con pan, vino, vestido y calzado ${ }^{139}$, lo cual podría tener un valor simbólico tal como lo tiene la retribución con caballos o con espadas.

Las prestaciones de hospitalidad forman parte de los deberes de quienes toman niños para crianza y reciben tierras a cambio de lealtad, según la literatura sobre el

133 "Cum tale foro de mare ad mare, ad rei, ad conde, ad infancone, ad quale dono uoleris in ipso solare sedente medio die et media ora", Archivo Catedral de León, doc. 1233 (1084).

134 "Cum tale foro cum quale ad me illud dedit domne Munnia; que pergas cum eo media die et media ora inter casata de Vani Mirel ad quale tibi melius fecerit sedente in ipso solare", Sahagún, doc. 811 (1084).

135 "Et isto solare per foro damus ad uobis que in illo abitante non pectet rosso neque omicidio neque fossadera neque osas pro muliere neque nulla calumnia”, Sahagún, doc. 1125 (1105).

${ }^{136}$ Sahagún, doc. 824 (1086).

137 "Et abet foro ipso solare que non faciat fossatera, et non faciat anubda, et vadat cum illo solare ad quale domno quis bene fecerit in universo mundo", SERRAno, Luciano, Becerro Gótico de Cardeña, Valladolid, 1910, doc. CCXX (1069).

138 "Unum prandium semel in anno de debito in omnibus expensis, si contigerit me facere transitum per terram illam", Garcia de Valdeavellano, Luis, "El prestimonio. Contribución al estudio de las manifestaciones de feudalismo en los reinos de León y Castilla durante la Edad Media", $A H D E$, XXV (1955). Apéndice documental, doc. XII.

139 "Accepimus de uobis in pretio, in pane et in vino et in vestire et in calcare, apreciatura in CL solidos", Sahagún, doc. 824 (1086). 
tema ${ }^{140}$. A este tipo de servicios se refiere el canciller López de Ayala cuando describe las primitivas behetrías: "en tales lugares pueden tomar Señor á quien sirvan é acojan en ellos qual quisieren" ${ }^{141}$. En una etapa previa a los ordenamientos sobre el tema (a los cuales el canciller se refiere después), los caballeros vinculados a estos lugares "comían de las viandas que alli fallaban" ${ }^{142}$, lo que parece aludir a contribuciones informales y voluntarias, consistentes con la idea de "acogimiento" que menciona antes el canciller.

El tránsito de obligaciones militares y contribuciones voluntarias de alimentos a la satisfacción de rentas agrarias ha sido considerado por los historiadores en relación al problema del surgimiento de relaciones de explotación feudales. Carlos Astarita ha propuesto la idea de un estadio transicional, que en términos generales corresponde, en el área estudiada (considerada globalmente), a los comienzos del siglo $\mathrm{x}$, y que se expresa en fórmulas imprecisas donde el tributo no se concibe todavía como ingreso regular y permanente ni tiene aún una composición estable; prevalecen en cambio modalidades de exigencia que contemplan la voluntad de los pobladores ("quantum poterint ad comite", etc.) ${ }^{143}$. En las sociedades tribales del norte de Europa el pasaje al modo de producción feudal se manifiesta, según Wickham, en la transformación del tributo "tribal", una forma de contribución ligera, en rentas más complejas, gravosas y susceptibles de comercialización; también es expresión del tránsito a relaciones de explotación la exigencia de tributos de hospitalidad por parte de un número creciente de personas (oficiales, delegados, etc.) ${ }^{144}$. En nuestro caso, la transformación de los servicios voluntarios prestados por los homines de benefactoria en rentas agrarias representa la incorporación plena de estos sujetos y sus formas sociales a la dinámica feudal dominante en el área, por lo cual constituye un aspecto del proceso general de expansión del feudalismo sobre espacios libres.

La exigencia de una renta de composición definida aparece asociada a la benefactoría o behetría (no hay un término unívoco en el periodo en cuestión) en documentación de fines del XI y comienzos del XII. En el fuero otorgado en 1125 por Gutierre Fernández a los habitantes de San Cebrián, a quienes se concede la facultad de cambiar de señor ("do vobis benefetria... ut tornetis ad qualem seniorem volueritis quem villa mandauerit"), se establecen las cantidades a pagar en concepto de renta. Se trata de un fuero ventajoso, que exime a los pobladores de nuncio, fonsadera y mañería y reduce a la mitad la multa por homicidio; a cambio, los pobladores se comprometen a pagar treinta panes o dos heminas de trigo, lo que cada cual prefiera ("qualem dator voluerit dare"), cierta cantidad de vino y un tocino o un carnero, siempre y cuando puedan obtener estos productos de sus heredades ("si colegerit de

140 PARKeS, "Celtic fosterage", p. 363.

141 López de Ayala, Pedro, Crónicas, Barcelona, 1991. Crónica de Don Pedr o I, Año Segundo, cap. XIV, p. 42. Concuerdan con esta interpretación BARBEro, Abilio y Loring GarcíA, María Isabel, “«Del palacio a la cocinal»: estudio sobre el conducho en el Fuero Viejo”, En la España Medieval, 14 (1991), p. 41.

142 López de Ayala, Crónicas, Crónica de Don Pedro I, Año Segundo, cap. XIV, p. 42.

143 Astarita, "Prácticas el conde", p. 34.

144 WicкHAм, Framing, pp. 344-349. 
sua heriditate det istum forum, et si non colegerit non det") ${ }^{145}$. Esta condición, que señala un antecedente de la adaptación de la renta al nivel de riqueza de los contribuyentes, podría también ser expresión de una etapa formativa de las nuevas relaciones sociales (la imposición de cargas a homines de benefactoria), donde el tributo, aunque obligatorio y definido, todavía conserva, al menos retóricamente, el carácter de provisión más o menos flexible de alimentos. El siguiente título del fuero confirma que la entrega de una parte del excedente agrario se presenta formalmente como un intercambio recíproco: el señor está obligado a ofrecer al concejo una comida ("et dominus det concilio... unum iantarem"), y debe alimentar también a los caballeros y peones que acudan a su llamado ${ }^{146}$. Por último, los habitantes darán dos días al mes de prestaciones de trabajo, que el señor deberá retribuir con pan, vino y duos conduchos, lo que en este contexto probablemente alude a las provisiones que se consideren necesarias ${ }^{147}$. Es de notar que mientras se grava a los productores directos con renta en especie y trabajo, el yantar y el conducho, dos característicos tributos de hospitalidad, se exhiben como obligaciones del señor, con lo cual la transferencia de excedentes se concreta manteniendo el formalismo de la retribución. Al igual que en el caso de las prácticas analizadas previamente, la lógica feudal dominante en el área introduce nuevos contenidos conservando aspectos de la costumbre, aunque en este caso, a diferencia de las benefactorías de comienzos del XI, los arcaísmos son marginales, y los nuevos contenidos expresan la incorporación plena de estas formas sociales al modo de producción feudal. Esto se observa en el fuero de Andaluz otorgado por Gonzalo Núñez en 1089, que concede franquicias y establece las cantidades que pagarán los pobladores; éstos pueden elegir señor entre los miembros del linaje del conde que les otorga el fuero; aquel que resulte elegido ofrecerá a la comunidad un banquete ("quando entrare sennor nuevo a la villa de al conceio todo yantar de pan e vino e carne") ${ }^{148}$.

La pervivencia de prestaciones de alimentos por parte del señor y las comidas que éste ofrece al concejo que lo ha elegido o aceptado como jefe podrían tener un antecedente en la práctica del potlatch, principal instrumento de legitimación de jefaturas en la sociedad arcaica. Mauss ha establecido que esta forma de distribución de riqueza constituye el principal mecanismo para el mantenimiento de la autoridad del jefe, que sólo mediante el acto de dar y ostentar su fortuna y cualidades especiales obtiene el reconocimiento de la comunidad y de los demás jefes, a quienes a su vez subordina mediante la obligación de retribuir el don ${ }^{149}$. En la saga de Laxdcela este tipo de práctica se relaciona con la necesidad de legitimación: el multitudinario banquete que ofrece Olaf el pavo real, prestigioso goði, en memoria de su padre, que

145 Lo mismo se establece en relación a los demás productos: "si habuerit porcos aut oves det, et si non habuerit non det”, Fuero de San Cebrián (1125), tit. 15, HinojosA, Documentos, XXXIII, p. 53.

146 "Et illo cavallero vel illo pedone quid dominus mandaverit ire in mandaderia... det dominum cibum illi", Fuero de San Cebrián, tit. 12, Ibidem.

147 "Et dominus det illis in duobus diebus panem tritici et vinum et duos conduchos et in tertio die panem et vinum et carnem ad suficiendum", Fuero de San Cebrián, tit. 17, Ibidem.

148 Fuero de Andaluz, 1.

149 Mauss, The gift, pp. 37-41; Mauss, "Don, contrato, intercambio", en Sociedad y ciencias sociales, pp. 27-32. 
lo ha favorecido en el reparto de la herencia pese a ser hijo ilegítimo, tiene el propósito de validarlo públicamente como genuino merecedor del favoritismo de su padre y de los apoyos que este último gozaba ${ }^{150}$.

La obligación del señor de ofrecer comidas a sus dependientes puede comprenderse como elemento residual de la liberalidad del estrato superior de la comunidad arcaica, que legitimaba su autoridad mediante la ostentación pública. Este elemento del funcionamiento social primitivo, que concierne únicamente a los jefes, expresa un aspecto complementario del proceso por el cual los sujetos portadores de la lógica feudal introducen la relación de explotación mediante la conservación formal de usos antiguos, de los cuales ellos mismos se desprenden progresivamente.

En la legislación del siglo XII se observa la tendencia a la sustitución de las comidas públicas por pagos en dinero a los concejos que las organizan: el señor debe pagar el costo de la comida que consume cuando visita los lugares sometidos a su dominio. El fuero de Lara de 1135 establece que el señor del lugar y su gente serán agasajados con una comida cuando se presenten en la villa, la cual organizará el concejo y deberá ser retribuida; para este fin las autoridades concejiles deben tasar el alimento consumido por el señor, quien deberá pagarlo o dar fiadores, caso contrario los hombres del concejo podrán privarlo de víveres sin ser penalizados ${ }^{151}$. Se observa, por un lado, la conversión de las comidas ofrecidas por el señor en pagos en dinero, y por otro, la conversión de la hospitalidad espontánea de los moradores en prestaciones obligatorias.

La referencia al servicio de posada en fueros del XII donde se regula la elección de señor o se alude a este derecho confirma que la hospitalidad hacia el benefactor era una práctica corriente, y que empieza a reglamentarse en el periodo en cuestión. Esta reglamentación se orienta a delimitar el grupo de prestadores, que tiende a identificarse con sectores campesinos: el fuero de Lara de 1135 exime a los que tuvieran caballo y a los clérigos de la obligación de dar albergue ${ }^{122}$; el fuero de Villadiego de 1134 exceptúa a caballeros y clérigos ${ }^{153}$; la normativa dada a los pobladores de Villavicencio en 1156 libera a los caballeros de la obligación de hospedar al señor ${ }^{154}$.

Esta legislación, por la cual la obligación de dar posada recae únicamente en los labradores, convive con otra donde se contempla de forma ambigua la voluntad de estos últimos, y a la vez se pone en evidencia que las prestaciones de hospitalidad

${ }^{150}$ Laxdcela saga, 27.

151 Quando uenerit dominus Lare in illam ciuitatem, accipiat ille iudex cum suo saione karne por espesa, et aprecient illam karnem homines de conceio, et det fidiatore [en blanco] merino et pectet eum; nisi non dederit fidiatore illo merino, tollat eum et non habeat calumnia, Fuero de Lara (1135), tit. 38, Martínez Díez, Fueros locales, doc. XIII, p. 141.

152 "Quando uenerit dominus Lare in illam ciuitatem, per mano de illo saione accipiant illos caualleros posadas, et non posent in casa de qui cauallo ouiere, necque in casa de uidua necque in casa de clerico, nisi fuerit clericus", Fuero de Lara (1135), tit. 44, Ibidem, p. 142.

153 "Et in casa de cauallero neque de clerigo neque de vidua non posset nullus homo", Fuero de Villadiego (1134), tit. 13, Ibidem, doc. XI, p. 137.

154 "Et qui pausare voluerit in illa villa, pauset in suis et postquam casas de suos homines fuerint plenas pausent per alios, set non in casa de caballero", Concordia otorgada en el año 1156 entre el abad de Sahagún y doña María Gómez y sus hijos sobre el señorío de Villavicencio, en la que se adicionan y modifican los fueros de la villa, MuÑoz y Romero, Colección de fueros municipales, p. 176. 
están siendo exigidas por la fuerza. Esto se observa en el fuero de Escalona de 1130, en uno de cuyos títulos se lee: "posadas per forcia, non donent" 155 . En un estudio sobre el vocabulario latino en la normativa carolingia relativa a la renta Kuchenbuch sugiere que el verbo donare, de uso infrecuente y adscripto únicamente a mansos libres, sería un indicador del mejor estatus de las personas a las que se exige el tributo, y que su utilización no expresaría un arcaísmo sino imposiciones nuevas ${ }^{156}$; de acuerdo a este criterio el fuero de Escalona, al igual que el resto de la normativa citada, reflejaría la tendencia a la obligatoriedad de la posada y su imposición a personas no gravadas antes con tributos.

La retórica ambivalente de la imposición de este tipo de cargas a hombres libres, que se refiere a la vez a la voluntad de los habitantes y a la violencia señorial, se observa en el fuero de Belbimbre de 1187: en relación a las prestaciones de hospitalidad, uno de sus títulos prescribe que el señor no irrumpa brutalmente en la casa del juez ${ }^{157}$; en otro título la voluntad del anfitrión se considera después de tres días de posada obligatoria ${ }^{158}$.

La regulación de las prestaciones de hospitalidad, comprendiendo las obligaciones de señores y campesinos y los abusos de los primeros, tiene su mayor desarrollo en las disposiciones del Fuero Viejo de Castilla y el Ordenamiento de Alcalá de Henares relativas a behetrías, que establecen la forma en que los habitantes deben ofrecer alimentos, vestido y posada a sus señores, los diviseros, y el pago que éstos deben efectuar por el conducho recibido, el cual deben consumir in situ ${ }^{159}$. Los textos donde se regulan estos servicios remiten a ordenamientos anteriores provenientes de las cortes de Nájera ${ }^{160}$, cuya existencia los historiadores han confirmado y situado

${ }^{155}$ Muñoz y Romero, Colección de fueros municipales, p. 487.

156 Kuchenbuch, Ludolf, "Porcus donativus: Language Use and Gifting in Seigneurial Records between the Eight and the Twelfth Centuries", Negotiating the Gift, pp. 206-209.

157 "In domo iudicis nullus dominus uiolenter hospitetur", Fuero de Belbimbre y sus cuatro aldeas (1187), tit. 17, Martínez DíeZ, Fueros locales, doc. XXIX, p. 180.

158 "In quacumque domo prestamerum hospitali contingerit... ultra trium dierum spacium contra uoluntatem hospitis sui prestamerus solo uno momento moram non faciat", Fuero de Belbimbre y sus cuatro aldeas, tit. 10, Ibidem, p. 179.

159 "Quando quisier venir á la viella (el divisero), deve tomar conducho un suo ome, e devenlo apresciar omes bonos de la viella, e el develo pagar fasta nueve dias de dineros, o peños... e deve posar en cualquier casa", Códigos españoles concordados y anotados, I, Madrid, 1872: Fuero Viejo de Castilla y Ordenamiento de Alcalá de Henares de 1348 (en adelante $F V C$ y $O A$ ), FVC, I, VIII, 1; "De esta guisa deven los fijosdalgo de Castiella pedir, e tomar conducho en las Behetrías, onde son deviseros: quando a ella quisieren venir, imbiar á delante a suos omes con sus cartas abiertas... e repicar la campana... E si se ayuntar no quisieren por el repicar de la campana, que el ome del señor develes prender el ganado", $F V C$, I, VIII, 2; el divisero exigirá posada, alimentos y ropa, $F V C$, I, VIII, 3; el huésped debe dar paja para los caballos y vino, $F V C$, I, VIII, 1; leña, FVC, I, VIII, 4; hortalizas, FVC, I, VIII, 5; todo lo cual debe ser supervisado por hombres buenos porque si los Escuderos, "ó los omes de los escuderos, ó los rapaces fuesen en su cabo á las casas sin otros omes buenos de la Aldea, que podrían quebrantar las arcas, é los cilleros, é tomar lo que quisieren, é despues negar que lo non tomaron", $O A$, XXXII, XXVIII.

160 "Porque fallamos que el Emperador Don Alfonso en las Cortes que fiço en Najera, establesció muchos ordenamientos... é declaramos algunas cosas de las que en dicho ordenamiento se contienen, que fallamos que eran buenas", $O A, \mathrm{XXXII.}$ 
hacia el final del siglo xII; Barbero y Loring García estiman que las leyes en cuestión pudieron redactarse entre 1184-1185 $5^{161}$. A esta legislación hace referencia el canciller López de Ayala ${ }^{162}$. La redacción de estos ordenamientos, cuyo espíritu concuerda con el de los fueros del periodo, tal vez responde a la necesidad de regular las relaciones de los pobladores con los hidalgos entre quienes eligen jefe, probablemente los miembros del linaje de mayor influencia en el lugar, que intentan formalizar su condición de potenciales señores y materializar en rentas definidas su derecho a ser elegidos como tales.

\section{CONCLUSIONES}

Las primitivas situaciones de benefactoría que se documentan durante el siglo XI en el área castellano-leonesa expresan prácticas sociales derivadas del modo de producción campesino, que se desarrollan en los intersticios de un espacio donde las relaciones feudales predominan pero no se han constituido plenamente.

Los beneficiados pueden ser milites, personajes destacados, campesinos libres o sirvientes y collazos promovidos a un status superior. Exceptuando el caso de estas dos últimas categorías de personas, a quienes eventualmente se les exige renta, las relaciones de benefactoría en este período no se fundan en la extracción de excedentes sino en vínculos relativamente laxos que involucran servicios diferenciados de la renta, principalmente servicios militares, de crianza y de hospitalidad. Los benefactores, en general miembros de familias condales, retribuyen estos servicios con tierras, caballos y apoyo en los tribunales. En forma semejante a las jefaturas campesinas, este vínculo es en principio inestable, pues los beneficiados prestan su apoyo voluntariamente y pueden modificar su lealtad dentro de ciertos límites determinados funcionalmente. Las restricciones en cuanto a la elección de jefe, sin embargo, tienden a imponerse desde los inicios, limitando la capacidad de elección de señor a una fórmula expresiva de otros contenidos.

Mayormente se apela a la fórmula de la benefactoría ("vadas ubi volueris", etc.) para indicar la condición jurídica libre del beneficiado cuando éste es un miles, un presbítero o un campesino de quien se esperan servicios no agrarios. En la medida en que la facultad de libre elección resulta negada por la imposición de servir a una misma familia, esta facultad, limitada a un formulismo, ya no implica incidencia política de estos sectores en las redes de poder aristocráticas. Esta evolución, latente en los pactos de benefactoría del XI, es expresión de la tendencia general, según la cual las prácticas derivadas del modo de producción campesino conservan su forma y modifican su contenido en función del contexto feudal en que se inscriben. Al respecto, la incorporación de los beneficiados a la "feudalidad", es decir, su conversión

161 Barbero y Loring García, "Del palacio y la cocina”, p. 27 y ss.

162 "E pusieron los dichos caballeros entre sí sus ordenamientos, que si alguno dellos tuviese tal lugar para le guardar, que non rescibiese daño ni desaguisado de los otros, salvo que les diese viandas por sus precios razonables; e si por aventura aquel caballero no los defendiese e les ficiese sinrazón, que los del lugar pudiesen tomar otro de aquel linage qual a ellos plugiese", López DE AYALA, Crónicas, Crónica de Don Pedro I, Año Segundo, cap. XIV, p. 42. 
en vasallos, es una de las evoluciones posibles, que tal vez se concretaba entre los homines de benefactoria socialmente más cercanos a la aristocracia.

El vocabulario de la benefactoría se utiliza también para formalizar la promoción de collazos y criados a un status superior. En estos casos el interés en la promoción podría explicarse por la pervivencia, en el seno de la aristocracia, de vinculaciones personales con sectores inferiores que todavía conservan su antigua significación, como en el caso del padrinazgo ejercido por sirvientes sobre miembros de familias condales.

Las prácticas sociales originarias del modo campesino contienen a su vez elementos que favorecen el avance de la lógica feudal. El padrinazgo, por ejemplo, constituye en sociedades campesinas una forma de intercambio de dones funcional al conflicto interfamiliar, cuya sustancia lleva implícita la indisolubilidad del vínculo. En el caso de la relación de benefactoría, donde el benefactor es a la vez jefe y padrino o apadrinado, el contenido esencial de la práctica campesina resulta funcional al interés aristocrático, por cuanto estimula la formación de clientelas permanentes y desalienta la opción de trasladar apoyos entre diversas familias aristocráticas. De esta manera el vínculo de crianza, propio de sociedades campesinas, favorece la tendencia a la desnaturalización de la elección de jefe y por lo tanto contribuye a degradar la autonomía política de los propietarios libres.

De manera similar, la entrega de tierras para retribuir servicios de mediación, una herramienta de negociación del estatus en sociedades campesinas, deviene funcional a la formación de patrimonio aristocrático en un contexto donde el ejercicio de la justicia constituye una fuente de ingresos. En este caso, de acuerdo a los ejemplos del área galaico-portuguesa, se observa la metamorfosis de la práctica campesina por efecto del contexto feudal, en el cual la mediación, y aun el desempeño de los jefes en la asamblea reproducen formas arcaicas, mientras el contenido de la praxis política estimula o presupone la absorción de propiedades y por ende reproduce relaciones de explotación feudales.

La consolidación de vínculos permanentes y hereditarios modifica la posición del benefactor, cuyos seguidores, a diferencia de aquellos que operan en sociedades campesinas, no tienen la opción de retirar su apoyo o brindárselo a jefes rivales si el benefactor defrauda sus expectativas. En la medida en que el mantenimiento de bases de sustentación política depende menos del desempeño del benefactor o la conformidad de los beneficiados (o en términos de Engels, en la medida en que el poder de función se independiza de la sociedad), la lógica aristocrática encuentra mayor espacio para desplegarse. Esto se traduce en la difusión de prácticas opresivas sobre los hombres libres, lo cual podría explicar la transformación de la entrega espontánea de alimentos en prestaciones obligatorias de hospitalidad, que en el periodo previo a su reglamentación los señores toman por la fuerza. La violencia señorial en relación a la posada y la consideración ambivalente de la voluntad de los pobladores en la legislación del XII podrían ser expresión de un periodo de avance señorializador de nuevo signo, que tiene como antecedente la participación de la aristocracia en la práctica campesina y la subordinación de sus contenidos a la lógica feudal de la totalidad, según se ha observado en la documentación del XI. 
Este proceso comprende también la desaparición gradual de donativos por parte del señor, que reemplaza el banquete por formas de liberalidad materialmente menos sustanciales, como la dotación ocasional de alimentos o los pagos a los concejos que le brindan hospitalidad. La pervivencia de estos pagos por parte del señor podría asociarse a su legitimación simbólica como extractor de tributos, que se concreta por mecanismos formalmente análogos a los que aseguraban su liderazgo en la sociedad preclasista.

La afirmación de estas tendencias, que expresan la expansión del feudalismo sobre nuevos espacios, se observa, en el área castellano-leonesa y en lo que concierne a la benefactoría, a partir de mediados del siglo XII, periodo en que se verifica la exigencia de tributos de hospitalidad por parte de todos los sujetos con derecho a la titularidad del señorío superior del lugar, generalmente miembros del mismo linaje; este desarrollo tiene su más detallada expresión en los ordenamientos surgidos de las cortes de Nájera de fines del XII.

Complementariamente a estos procesos se opera durante el XII la separación entre milites y campesinos, quedando los primeros exceptuados de tributos y de restricciones respecto a la elección de jefe y por ende en condiciones de incorporarse al sistema feudal como vasallos, y los últimos sometidos en forma permanente a un mismo linaje y obligados a tributar, es decir, excluidos del conjunto de hombres libres desde el punto de vista de sus facultades políticas y su capacidad de disponer de los frutos del trabajo. Esta escisión acompaña la expansión del feudalismo en su vertiente política (difusión del vasallaje) y económica (difusión de relaciones de explotación feudales), cuyo punto de partida hemos situado en la desnaturalización de la práctica campesina. 